\title{
A Magnetoelectric Hybrid Hydraulic Damper for the Mining Robot Suspension System
}

\author{
Kun Hu $\mathbb{D}^{1,2}$ Fei Li $\mathbb{D}^{1,2}$ Zhiyuan Zhang $\mathbb{D}^{3},{ }^{3}$ Shuang Wang $\mathbb{D}^{1,2}$ and Hao Jiang $\mathbb{D}^{2}$ \\ ${ }^{1}$ School of Mechanical Engineering, Anhui University of Science and Technology, Huainan 232001, China \\ ${ }^{2}$ State Key Laboratory of Mining Response and Disaster Prevention and Control in Deep Coal Mines, Huainan 232001, China \\ ${ }^{3}$ China Coal Science and Industry Group, Shanghai Research Institute Co., Ltd., Shanghai 200030, China
}

Correspondence should be addressed to Kun Hu; hukun991@163.com and Fei Li; 2698341084@qq.com

Received 10 April 2021; Revised 31 July 2021; Accepted 9 August 2021; Published 8 September 2021

Academic Editor: Mohamed A. A. Abdelkareem

Copyright (c $2021 \mathrm{Kun} \mathrm{Hu}$ et al. This is an open access article distributed under the Creative Commons Attribution License, which permits unrestricted use, distribution, and reproduction in any medium, provided the original work is properly cited.

\begin{abstract}
In order to improve the damping and controllability of the mining robot suspension system, a new magnetoelectric hybrid suspension hydraulic damper, which is a semiactive suspension damper, is proposed based on the traditional hydraulic damper by introducing the magnetic-electric hybrid suspension structure. The structure and working principle of the damper are introduced, respectively, and the mathematical models of the equivalent stiffness and equivalent damping of the system are calculated by the magnetic circuit method and the oil circuit method, while AMESim/Simulink cosimulation is carried out. In order to test the damping performance, a prototype of the magnetoelectric hybrid suspension hydraulic damper was fabricated. The results show that the vibration displacement amplitude can be reduced by $20 \%$ and the vibration acceleration amplitude can be reduced by $10 \%$ by adjusting the stiffness and damping of the system due to the magnetoelectric hybrid suspension structure. Moreover, the experimental results are consistent with the simulation results, which verify the effectiveness and superiority of this type of damper.
\end{abstract}

\section{Introduction}

As a new type of intelligent mining equipment, mining robot has become a research focus in recent years due to its characteristics of automation and high efficiency $[1,2]$. The working environment in underground coal mines is usually very harsh, and the floor is uneven, which has a great impact on the normal operation of the robot. In particular, it is easy to damage the precision instruments and equipment during the visual data collection, resulting in unnecessary losses [3]. In order to reduce the impact and vibration of mining robot and ensure the stable and efficient work efficiency, it is urgent to research and develop suitable suspension systems for mining robots.

The main function of the suspension is to cushion road impact and suppress body vibrations caused by road surface unevenness. Depending on the level of controllability of damping, suspension systems are classified as passive, active, and semiactive [4]. Passive suspension control solutions are low cost and consist of springs and dampers with fixed properties, but these specifications are not adjustable. Active suspension is a system that adds an active controller, which actively generates the corresponding damping force according to different external disturbances as a way to adjust the movement of the body. The practical application of active suspension in vehicles is limited due to its higher power consumption and lower reliability [5]. Semiactive suspension is widely used, which does not require high power semiactive suspension, while it adjusts the damping characteristics by means of low power signals. On the other hand, the semiactive suspension can work as a passive suspension when the controller fails [6].

At present, the most studied mode of vibration reduction is semiactive suspension. Semiactive suspension mainly uses air suspension, pneumatic suspension, and other methods to reduce vibration by improving damping adjustment structure [7, 8]. Gokul and Malar [9] studied the static vertical stiffness characteristics of the air spring in the air suspension 
system. Sang et al. [10] studied the characteristics of doublechamber hydrocarbon suspension. Nieto et al. [11] designed a pneumatic suspension capable of adapting to incoming vibrations, performing a switching control strategy between two different configurations. Maciejewski et al. [12] proposed the use of pneumatic muscles to achieve active vibration control of horizontal seat suspensions. Pintado et al. [13] proposed a fusion index measured by a thermodynamic model of a pneumatic vibration isolator to obtain a simple model of the airflow of the limiter. Zhu et al. [14] studied a new type of semiactive dual-chamber hydropneumatic inerter-based suspension. Zhao et al. [15] proposed an integrated sliding mode control-two-point wheelbase preview strategy for the semiactive air suspension system with a gasfilled adjustable shock absorber. Although air suspension and pneumatic suspension have been applied to some extent, the leakage problem, Jeyasenthil and Choi [16] and Huang et al. [17], has been restricting their development.

The electromagnetic suspension system stands out as a new concept of the semiactive or active suspension system, which focuses on stiffness regulation and studies how to reduce the vibration amplitude of the system, which is very consistent with the operating conditions of mining robot [18]. Ding et al. [19] analyzed the three-dimensional numerical calculation and optimization of electromagnetic suspension stiffness in maglev trains. Emre and Pinar [20] proposed a systematic research approach based on improving the lateral sway stiffness of suspensions. Babak et al. [21] studied a hybrid electromagnetic damper to solve a series of problems. Maciejewski et al. [22] studied the modeling process and control strategy of a semiactive seat suspension system with magnetorheological dampers (MR). Mohammed and Alktranee [23] used three strategies to study the behavior of suspension systems. Jamadar et al. [24] proposed a mathematical model for equivalent damping based on magnetorheological dampers (MR). Ding et al. [25] designed a new hybrid electromagnetic actuator and its control system. Gysen et al. [26] deduced several specifications for the design of electromagnetic suspension systems. Although electromagnetic suspension has been deeply studied by scholars for a long time, the application of magnetoelectric hybrid suspension structure is rare. This structure interacts with permanent magnet through electromagnet, which has the advantages of large force and quick response [27, 28]. This study designs a magnetoelectric hybrid suspension structure based on the traditional hydraulic damper and proposes a new type of the hydraulic damper for magnetoelectric hybrid suspension.

\section{Structure and Working Principle}

2.1. Principle of Magnetoelectric Hybrid Suspension. The principle of magnetoelectric hybrid suspension is that the electromagnet and the permanent magnet are formed into a group of corresponding components. Because of the magnetic pole, there is magnetic force between the two poles. There are many ways to realize electromagnetic force, among which the electromagnetic-permanent magnetic suspension structure is the simplest and most superior. Figure 1 shows the distribution mode.

The main advantages of electromagnetic-permanent magnet suspension structure are as follows:

(1) No contact: this is the main advantage of maglev, which can bring frictionless resistance, no mechanical wear, low energy loss, low noise, low maintenance cost, and a series of other advantages with a great application value

(2) Easy active control: electromagnetic force can be controlled only by changing the current, which can be applied in various systems that need vibration reduction and support hardness can be changed

(3) Energy saving: the coercive force, residual magnetic induction, and maximum magnetic energy product of permanent magnets are relatively large, which can provide a constant magnetic field with a relatively large intensity in a small volume;

2.2. Structure and Principle. In view of the above advantages and for the purpose of changing the system stiffness, this study proposes a magnetoelectric hybrid suspension hydraulic damper. Figure 2 shows the structure model.

The main components of the magnetoelectric hybrid suspension hydraulic damper are piston rod, working cylinder, electromagnet, permanent magnet, spring, and so on. The upper and lower supports are, respectively, connected with the car body and the tire. When the car body vibrates, the piston rod drives the electromagnet to move up and down, and the spring then compresses, stretches, and reciprocates. After being squeezed, the hydraulic oil continuously generates damping force through the valve opening of the damping valve to reduce the harmful vibration caused by the spring's own recovery. At the same time, because electromagnet and permanent magnet produce electromagnetic force relative to each other, the spring vibration can be enhanced or weakened. According to Lorenz's law, the electromagnetic force can be adjusted by changing the size and direction of the current in the electromagnet. In order to achieve the purpose of stable vibration reduction, when the spring vibration is larger, the electromagnetic force is reduced to reduce the spring vibration trend; when the spring vibrates less, the electromagnetic force is increased to increase the damping effect.

\section{System Dynamics Model}

3.1. Electromagnetic. The stiffness control of the magnetoelectric hybrid suspension hydraulic damper is realized by adjusting the electromagnetic force. The calculation process of the electromagnetic force is relatively complicated, which is usually calculated by the magnetic circuit method. In order to facilitate analysis and calculation, the following assumptions are made based on Figure 1:

(1) The leakage flux of the coil, air gap, and permanent magnet is zero 


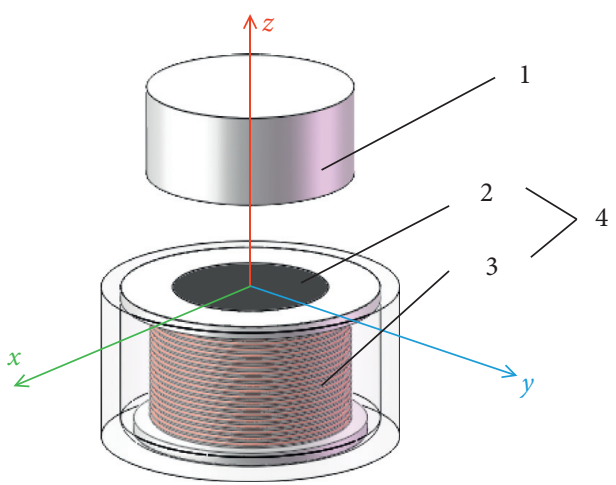

FIgURE 1: Magnetoelectric hybrid suspension. 1, permanent magnet; 2, iron core; 3, coil; 4, electromagnet.

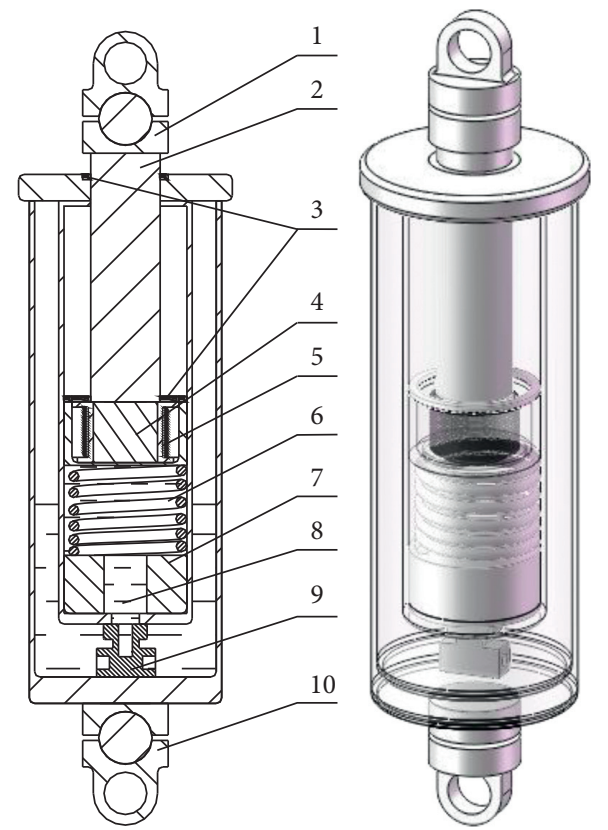

FIGURE 2: Structure model of the magnetoelectric hybrid suspension hydraulic damper. 1, upper support; 2 , piston rod; 3 , sealing ring; 4, iron core; 5 , coil; 6 , spring; 7 , permanent magnet; 8 , hydraulic oil; 9 , damping valve; 10, lower support.

(2) The magnetic resistance of the core is ignored, and the magnetic potential is considered to be evenly distributed on air gap and permanent magnets.

Figure 3 shows the simplified magnetic circuit diagram. According to the magnetic flux continuity theorem,

$$
B_{\delta} S=B_{m} S_{m}
$$

where $S$ is the cross-sectional area of the top of the core, $S_{m}$ is the magnetic pole area of the permanent magnet, $B_{\delta}$ is the air gap magnetic flux density, and $B_{m}$ is the magnetic flux density of the permanent magnet.

According to the Ampere loop theorem,

$$
N i=H_{m} d_{m}+H_{\delta} z \text {. }
$$

High performance of the sintered $\mathrm{NdFeB}$ permanent magnetic material N48 is selected, with remanence of $B_{r}$ and residual coerced force of $H_{c}$. The relationship between the flux density of the permanent magnet and the magnetic field strength and coercivity is as follows:

$$
\begin{aligned}
B_{m} & =\frac{B_{r}}{H_{c}} H_{m}+B_{r}, \\
B_{r} & =\mu_{0} \mu_{r} H_{c},
\end{aligned}
$$

where $\mu_{0}$ is the vacuum permeability and $\mu_{r}$ is the relative permeability of the permanent magnet.

Magnetic flux density at the air gap is

$$
B_{\delta}=\mu_{0} \frac{N i+H_{c} d_{m}}{z+\left(d_{m} S / \mu_{r} S_{m}\right)},
$$

where the second term of the molecule on the right side of the equation is another magnetomotive force $H_{c} d_{m}$ generated after the magnetic circuit is connected to a permanent magnet. 


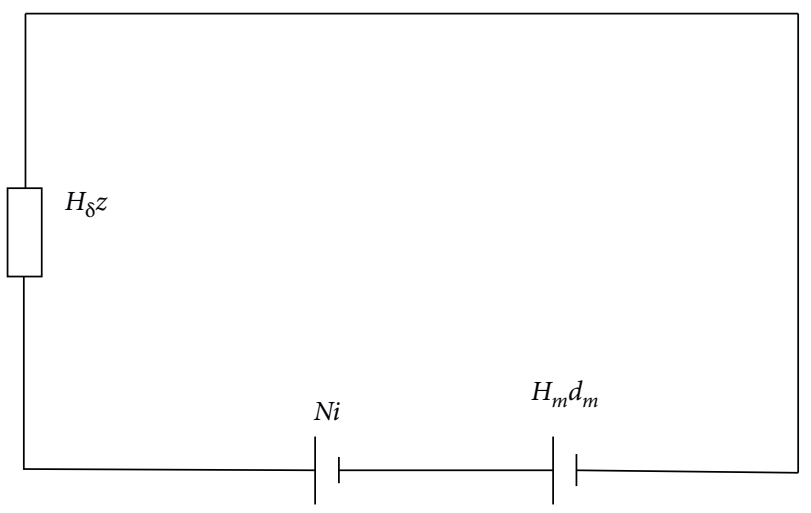

Figure 3: Simplified magnetic circuit of electromagnetic-permanent magnet mixed suspension. $z$ is the suspension gap, $d_{m}$ is the thickness of the permanent magnet, $N$ is the number of turns of the magnet coil, $i$ is the current passing through the electromagnetic coil, $H_{\delta}$ is the magnetic field strength of the air gap, and $H_{m}$ is the magnetic field strength of the permanent magnet.

At any instant, the magnitude of the electromagnetic force between the permanent magnet and the electromagnet is

$$
\begin{aligned}
F & =\frac{B_{\delta}^{2} S}{2 \mu_{0}}=\frac{\mu_{0} S\left(N i+H_{c} d_{m}\right)^{2}}{2\left(z+d_{m} S / \mu_{r} S_{m}\right)^{2}}, \\
& =\frac{\mu_{0} S}{2}\left(\frac{N i+H_{c} d_{m}}{x_{e}}\right)^{2}=\frac{\mu_{0} S}{2}\left(\frac{N U_{m}+H_{c} d_{m} R_{m}}{x_{e} R_{m}}\right)^{2},
\end{aligned}
$$

where $x_{e}$ is the equivalent air gap of the system, $U_{m}$ is the voltage through the electromagnetic coil, and $R_{m}$ is the resistance of the electromagnetic coil.

When $d_{m}=0$, equation (5) is converted to

$$
F^{\prime}=\frac{\mu_{0} S}{2}\left(\frac{N i}{x_{e}}\right)^{2}=\frac{\mu_{0} S}{2}\left(\frac{N U_{m}}{x_{e} R_{m}}\right)^{2} .
$$

Equations (5) and (6), respectively, represent the expressions of electromagnetic force in magnetoelectric hybrid suspension (permanent magnet) and pure electromagnetic suspension (ordinary conductor) models. By comparing the two equations, it can be seen that, unlike the pure electromagnetic suspension model, the electromagnetic force in the magnetoelectric hybrid suspension model is no longer proportional to the square of the current and inversely proportional to the square of the air gap due to the thickness of the permanent magnet, but shows a nonlinear relationship. When the structure parameters of the permanent magnet are determined, the electromagnetic force expression of the controlled parameter is only the value of the voltage through electromagnetic coil $U_{m}$. Due to the residual coercivity of permanent magnets $H_{c}$ is more giant, under the same input voltage value, the magnetoelectric hybrid suspension system of electromagnetic force $F$ than pure electromagnetic suspension of the electromagnetic force $F^{\prime}$, the magnetoelectric mixed suspension structure is more energy efficient.
3.2. Damping Force. The analysis of damping force needs to be calculated through the oil circuit diagram. Figure 4 shows the simplified oil circuit diagram of the magnetoelectric hybrid suspension hydraulic damper.

In Figure $4, D_{1}$ is the diameter of the piston rod, $D_{2}$ is the diameter of the inner cylinder, $d$ is the diameter of the throttle hole in the damping valve, $n$ is the number of throttle holes, $P_{1}$ is the pressure in the inner cylinder, $P_{2}$ is the pressure in the outer cylinder, and $v$ is the movement speed of the piston cylinder.

Based on the above simplified oil circuit diagram, the flow through the damping valve is

$$
Q=C C_{z} A_{1} \sqrt{\frac{2 \Delta P}{z \rho}}
$$

where $C$ is the flow coefficient of the throttle hole, whose value is related to the geometric shape of the damping hole, generally, $0.6-0.8$ is taken, $C_{z}$ is the flow correction coefficient between the damping holes, $A_{1}$ is the area of the damping hole, $A_{1}=\pi d^{2} / 4, \Delta P$ is the cylinder pressure difference inside and outside, and $\Delta P=P_{1}-P_{2}, \rho$ is the oil density.

The volume of piston rod flowing into the external cylinder shall be equal to the flow through the damping valve, i.e.,

$$
Q=A_{2} v
$$

where $A_{2}$ is the cross-sectional area of the piston rod, $A_{2}=\pi D_{1}^{2} / 4$.

It can be obtained from equations (7) and (8):

$$
v=C C_{z} \frac{d^{2}}{D_{1}^{2}} \sqrt{\frac{2 \Delta P}{n \rho}} .
$$

The damping force expression can be obtained from equation (9):

$$
F_{c}=\frac{A_{2} K\left(x+x_{0}\right)}{A_{3}}+\frac{\rho n A_{2}^{3} v^{2}}{2 C^{2} C_{z}^{2} A_{1}^{2}},
$$

where $K$ is the spring stiffness, $x_{0}$ is the initial compression amount of the spring, $x$ is the compression amount of the spring after the movement of the piston rod, $A_{3}$ is the crosssectional area of the inner cylinder, and $A_{3}=\pi D_{2}^{2} / 4$.

3.3. Road Excitation. The input of body vibration mainly comes from the unevenness of the road surface, i.e., the effect of road excitation on body vibration. According to whether the pavement excitation is continuous or not, it can be divided into discrete pavement excitation and random pavement excitation. Arched pavement, waveform pavement, and trapezoidal pavement belong to discrete pavement excitation. The rolled pavement belongs to the random type pavement excitation. The research object of this study is a mining robot, and the working environment is often accompanied by gangue, water, pits, and other pavements, and the environment has strong randomness, so the random pavement excitation is mainly studied.

Since the pavement excitation is random, it can be characterized by a spectral density function for better 


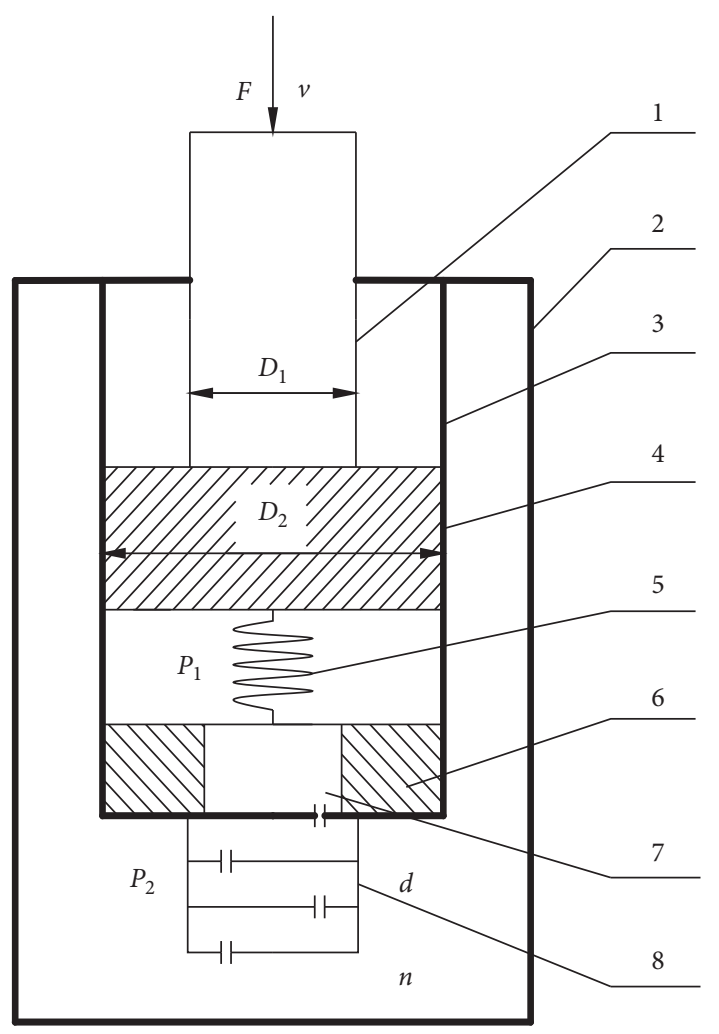

FIGURE 4: Simplified oil circuit diagram of the magnetoelectric hybrid suspension hydraulic damper. 1, piston rod; 2 , outer cylinder; 3 , inner cylinder; 4 , electromagnet; 5 , spring; 6 , permanent magnets; 7 , magnetorheological hydraulic oil; 8 , damping valve.

analysis and calculation. In ISO $8608: 1995(\mathrm{E})$, the pavement power spectral density $G_{q}(n)$ is recommended to be expressed as follows [29]:

$$
G_{q}(n)=G_{q}\left(n_{0}\right)\left(\frac{n}{n_{0}}\right)^{-W}
$$

where $G_{q}$ is the power spectral density of the pavement in the vertical direction in $\mathrm{m}^{3}, n$ is the spatial frequency, $n_{1}=0.01 \mathrm{~m}^{-1}, n_{0}$ is the corresponding reference spatial frequency, $n_{0}=0.1 \mathrm{~m}^{-1}, G_{q}\left(n_{0}\right)$ is the pavement unevenness coefficient, and $W$ is the frequency index, dimensionless number, and usually takes the value of 2 .

The function $G_{q}(n)$ is a statistical characteristic of the pavement, which is a definite value. In the analysis of the impact of road surface vibration of vehicles, only considering the pavement power spectrum density $G_{q}(n)$ is not comprehensive enough but also the role of vehicle speed should be considered. Let the time frequency be $f$, the vehicle speed be $v$, and the spatial frequency be $n$. The relationship is as follows:

$$
f=v n \text {. }
$$

In this study, the time domain research method is chosen, so the frequency domain model of the pavement must be converted into a time domain model. From equation (12), the conversion relationship between time and space spectrum is obtained as

$$
G_{q}(f)=\frac{1}{v} G_{q}(n) .
$$

When $W=2$, equations (11) and (12) are substituted into equation (13), and it can be deduced that

$$
G_{q}(f)=\frac{1}{v} G_{q}\left(n_{0}\right)\left(\frac{n}{n_{0}}\right)^{-2}=G_{q}\left(n_{0}\right) n_{0}^{2} \frac{v}{f^{2}}=G_{0} \frac{v}{f^{2}} .
$$

The road surface unevenness can be considered as a white noise $w(t)$ generated by a filter, from which the random excitation of the road surface can be obtained as [30]

$$
\dot{x}(t)=2 \pi \sqrt{G_{0} v} w(t) .
$$

Equation (15) is the time domain model of pavement excitation used in the vehicle suspension analysis, but the expression is not accurate enough when the pavement spectrum is in the low frequency band. In order to improve the accuracy and reliability of the model, a constant called the lower cutoff frequency $f_{0}$ is introduced here, and then, equation (15) becomes

$$
\dot{x}(t)=-2 \pi f_{0} x(t)+2 \pi \sqrt{G_{q}\left(n_{0}\right) v} w(t) .
$$

Internationally, the pavement unevenness is divided into 8 levels according to the degree of pavement excitation, as given in Table 1 [31].

3.4. System Vibration Mechanical Model. In order to study the semiactive suspension system in a simple way, a magnetoelectric hybrid suspension system based on a 2-DOF system with a $1 / 4$ travel mechanism was developed with integrity in mind. Figure 5 shows the vertical dynamics modeling of the semiactive suspension system, and Table 2 provides the meaning of the parameters.

According to Newton's second equation, the vibration differential equation of the $1 / 4$ walking mechanism semiactive suspension with 2-DOF is established as shown in the following equation [32].

$$
\left\{\begin{array}{l}
m_{s} x_{s}^{\prime \prime}+c\left(x_{s}^{\prime}-x_{u}^{\prime}\right)+k_{s}\left(x_{s}-x_{u}\right)=0, \\
m_{u} x_{u}^{\prime \prime}-c\left(x_{s}^{\prime}-x_{u}^{\prime}\right)-k_{s}\left(x_{s}-x_{u}\right)+k_{t}\left(x_{u}-x_{t}\right)=0 .
\end{array}\right.
$$

Assuming that the system state vector is

$$
X=\left[\begin{array}{llll}
x_{1} & x_{2} & x_{3} & x_{4}
\end{array}\right]^{T}=\left[\begin{array}{llll}
x_{s} & x_{u} & x_{s}^{\prime} & x_{u}^{\prime}
\end{array}\right]^{T},
$$

output vector is

$$
Y=\left[x_{s}^{\prime \prime}, x_{s}^{\prime}-x_{u}^{\prime}, k_{t}\left(x_{t}-x_{u}\right)\right]^{T},
$$

and input vector is

$$
U=\left[x_{t}, F\right]^{T},
$$

then the state equation is 


$$
\left\{\begin{array}{l}
X^{\prime}=A X+B U \\
Y=C X+D U
\end{array}\right.
$$

Combine equations (17) and (21) to get the following equation:

$$
A=\left[\begin{array}{cccc}
0 & 0 & 1 & 0 \\
0 & 0 & 0 & 1 \\
-\frac{k_{e}}{m_{s}} & \frac{k_{e}}{m_{s}} & -\frac{c_{e}}{m_{s}} & \frac{c_{e}}{m_{s}} \\
\frac{k_{e}}{m_{u}} & -\frac{k_{e}+k_{t}}{m_{u}} & \frac{c_{e}}{m_{u}} & -\frac{c_{e}}{m_{u}}
\end{array}\right],
$$

$$
\begin{aligned}
& B=\left[\begin{array}{cc}
0 & 0 \\
0 & 0 \\
0 & \frac{1}{m_{s}} \\
\frac{k_{t}}{m_{u}} & -\frac{1}{m_{u}}
\end{array}\right], \\
& C=\left[\begin{array}{cccc}
-\frac{k_{e}}{m_{s}} & \frac{k_{e}}{m_{s}} & -\frac{c_{e}}{m_{s}} & \frac{c_{e}}{m_{s}} \\
0 & 0 & 1 & -1 \\
0 & -k_{t} & 0 & 0
\end{array}\right] \text {, } \\
& D=\left[\begin{array}{cc}
0 & \frac{1}{m_{s}} \\
0 & 0 \\
k_{t} & 0
\end{array}\right] \text {, }
\end{aligned}
$$

where $A$ represents the state matrix, $B$ represents the input matrix, $C$ represents the output matrix, and $D$ represents the transfer matrix.

Equation (22) is the state equation required by the control system.

3.5. Equivalent Stiffness and Equivalent Damping. The various components of the semiactive suspension system are affected by each other. This effect is mostly nonlinear. Especially after the introduction of magnetoelectric hybrid suspension, the dynamic characteristics of the system will change. In order to better express the stiffness adjustment method of the new type of the magnetoelectric hybrid suspension hydraulic damper, it is necessary to analyze the overall vibration model of the semiactive suspension system and obtain the equivalent stiffness and equivalent damping expressions, respectively, according to the structure and working principle of the damper.

The equivalent stiffness of the system is mainly related to the spring stiffness and the electromagnetic force. The equivalent stiffness of the system is mainly related to the spring stiffness and electromagnetic force. Based on equations (5) and (17), the expression of equivalent stiffness $k_{e}$ can be obtained:

$$
\begin{aligned}
k_{s}\left(x_{u}-x_{s}\right)+F= & k_{e}\left(x_{u}-x_{s}\right), \\
k_{e}= & k_{s}+\frac{F}{x_{u}-x_{s}}=k_{s}+\frac{\mu_{0} S}{2\left(x_{u}-x_{s}\right)} \\
& \cdot\left(\frac{N U_{m}+H_{c} d_{m} R_{m}}{x_{m} R_{m}}\right),
\end{aligned}
$$

where spring stiffness $k_{s}$ and vacuum permeability $\mu_{0}$ are usually taken as 1.0, and core cross-sectional area $S$, coil turns $N$, residual coercive force $H_{c}$, coil resistance $R_{m}$, and permanent magnet thickness $d_{m}$ are all fixed parameters. Tire displacement $x_{u}$, fuselage displacement $x_{s}$, and suspension air gap $x_{m}$ are constantly changing with system vibration and cannot be actively adjusted. The only controllable parameter is the input voltage value $U_{m}$ of the solenoid coil. It can be seen from equation (24) that the equivalent stiffness of the system has a nonlinear relationship with the voltage value, and the increase or decrease of the voltage value will increase or decrease the system stiffness.

The equivalent damping of the system is mainly related to the damping force. The expressions of equivalent damping $c_{e}$ can be obtained by combining equations (10) and (17):

$$
\begin{aligned}
c_{e}\left(x_{s}^{\prime}-x_{u}^{\prime}\right) & =F_{c}=\frac{A_{2} k_{s}\left(x_{0}+x_{1}\right)}{A_{3}}+\frac{\rho n A_{2}^{3} v^{2}}{2 C^{2} C_{Z}^{2} A_{1}^{2}}, \\
c_{e} & =\frac{1}{\left(x_{s}^{\prime}-x_{u}^{\prime}\right)}\left[\frac{A_{2} k_{s}\left(x_{0}+x_{1}\right)}{A_{3}}+\frac{\rho n A_{2}^{3} v^{2}}{2 C^{2} C_{Z}^{2} A_{1}^{2}}\right],
\end{aligned}
$$

where the area of the damping hole $A_{1}$, the cross-sectional area of the piston $\operatorname{rod} A_{2}$, the cross-sectional area of the inner cylinder $A_{3}$, the initial spring compression $x_{0}$, the spring compression after the piston rod moves $x_{1}$, the oil density $\rho$, the number of throttle holes $n$, and the movement speed of the piston rod $v$ are not adjustable.

\section{AMESim/Simulink Modeling}

4.1. Establishment of the AMESim Model. AMESim software can greatly simplify the simulation model on the basis of maintaining the original function, and it is widely used in the automobile suspension system [33, 34]. Based on the vibration differential equations and operating principle of the magnetoelectric hybrid suspension and semiactive suspension, Figure 6 shows the AMESim model of the 2-degree-offreedom $1 / 4$ vehicle semiactive suspension system.

In this AMESim model, the mechanics module (green part) constitutes the main body of the semiactive suspension 
TABle 1: Classification criteria for unevenness of road surface.

\begin{tabular}{|c|c|c|c|}
\hline \multirow{2}{*}{ Road surface unevenness grade } & \multicolumn{3}{|c|}{$G_{q}\left(n_{0}\right) / 10^{-6} \mathrm{~m}^{3}$} \\
\hline & Lower limit & Geometric mean & Upper limit \\
\hline$A$ & 8 & 16 & 32 \\
\hline$B$ & 32 & 64 & 128 \\
\hline$C$ & 128 & 256 & 512 \\
\hline$D$ & 512 & 1024 & 2048 \\
\hline$E$ & 2048 & 4096 & 8192 \\
\hline$F$ & 8192 & 16138 & 32768 \\
\hline$G$ & 32768 & 65536 & 131072 \\
\hline$H$ & 131072 & 262144 & 524288 \\
\hline
\end{tabular}

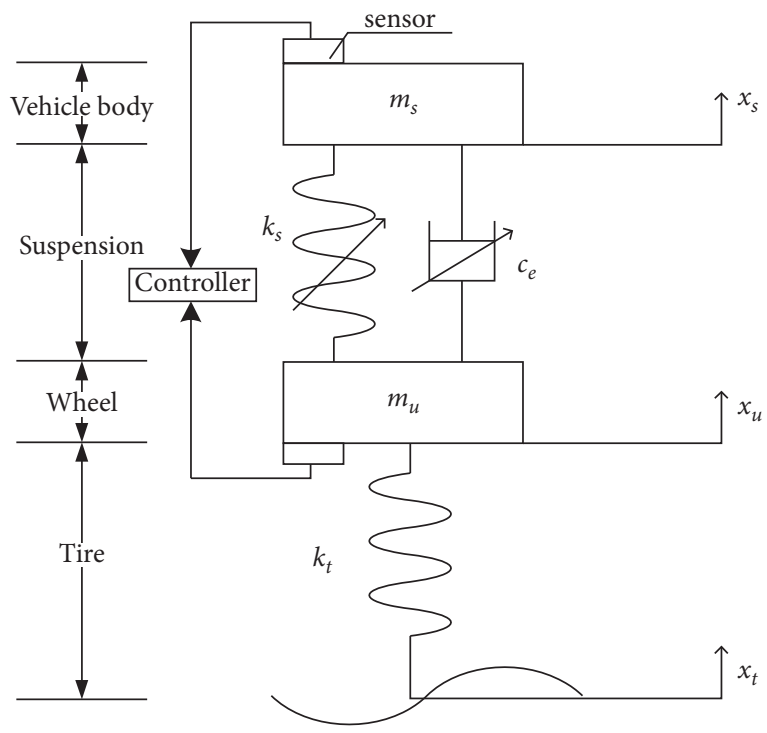

Figure 5: Suspension system vertical dynamics model.

TABLE 2: Semiactive suspension parameters.

\begin{tabular}{lcc}
\hline Parameters & Meanings & Units \\
\hline$m_{s}$ & Body weight (sprung weight) & $\mathrm{kg}$ \\
$m_{u}$ & Tire weight (unsprung weight) & $\mathrm{kg}$ \\
$k_{s}$ & Spring stiffness & $\mathrm{N} / \mathrm{mm}$ \\
$k_{t}$ & Tire stiffness & $\mathrm{N} / \mathrm{mm}$ \\
$c_{e}$ & Suspension equivalent damping & $\mathrm{N} /(\mathrm{mm} / \mathrm{s})$ \\
$x_{s}$ & Body displacement & $\mathrm{m}$ \\
$x_{u}$ & Tire displacement & $\mathrm{m}$ \\
$x_{t}$ & Road excitation displacement & $\mathrm{m}$ \\
\hline
\end{tabular}

system, including springs, damping, tire mass, car body mass, displacement module, force module, and displacement converter module. The electromagnetic module (the purple part) constitutes a magnetic-electric hybrid suspension system, including an electromagnet, a permanent magnet, a power supply, and an electromagnetic force output module. The signal module (red part) constitutes a signal and control system, including road excitation, signal integration and control, and feedback control.

In this model, a finite bandwidth white noise signal is used as the road excitation to generate vibration through a semiactive suspension system consisting of spring-tire- damping, spring, and electromagnetic force-body. The electromagnetic force is provided by electromagnets and permanent magnets. The joint MATLAB/Simulink simulation module collects and analyzes the spring-load displacement (Bdisplacement) and unspring displacement (Wdisplacement) signals and then outputs current signal to the electromagnets to control the electromagnetic force and the body displacement changes accordingly. This whole process forms a closed-loop feedback system. The main parameter information of the AMESim model of the magnetoelectric hybrid semiactive suspension is given in Table 3. 


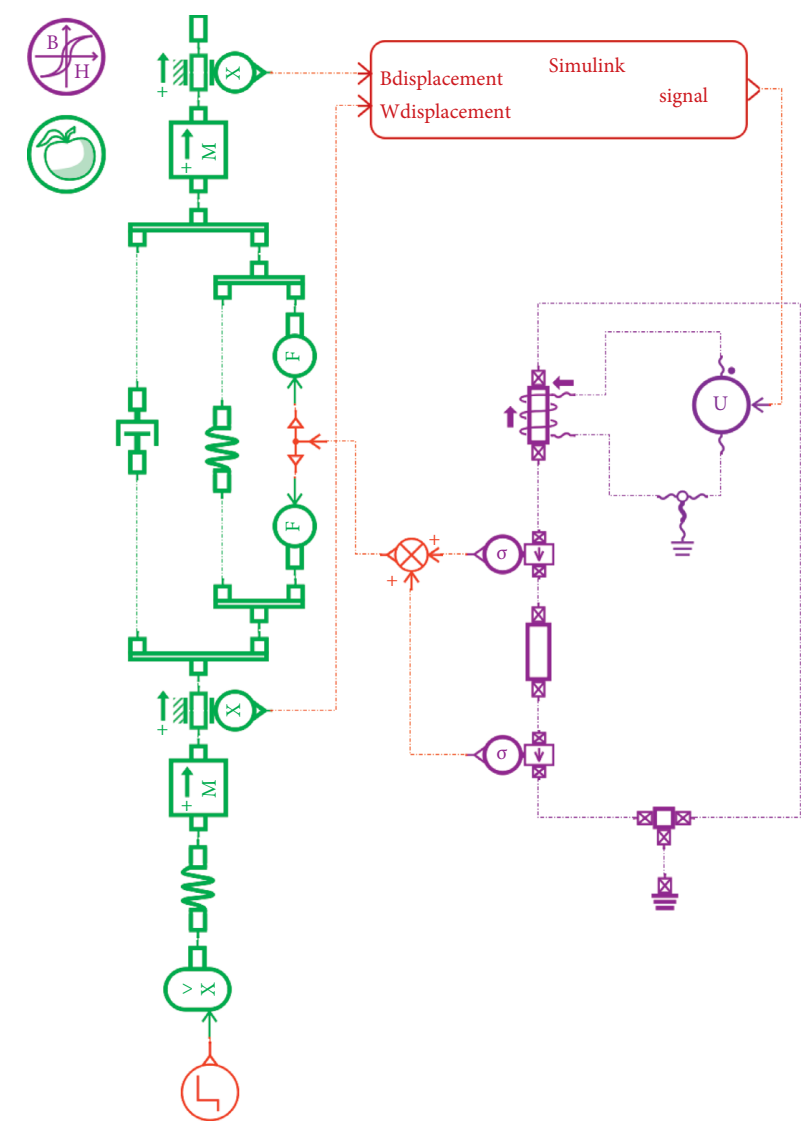

FIgURE 6: AMESim model of magnetoelectric hybrid semiactive suspension.

The established system model includes signal input, acquisition, processing, output, and feedback, which can more accurately simulate the working conditions of the magnetoelectric hybrid suspension, semiactive suspension system, which is beneficial to data analysis and research.

4.2. Establishment of Simulink Control Module. Similar to AMESim, the Simulink visual editor is widely used in the control field and can be used for joint simulation with AMESim with high efficiency and reliability. In the field of semiactive suspension control, the commonly used Simulink control strategies are fuzzy control, PID control, and optimal control.

In the loop control process, due to disturbance, the controlled parameter often deviates from the predetermined value, which will cause a certain system deviation between the measured value and the predetermined value. Then, the automatic adjustment unit performs proportional (P), integral (I), and differential (D) operations on the deviation signal that can reduce the error between the measured value and the predetermined value; finally, it will output a standard signal to realize automatic control of the parameter.

Based on the vibration differential equation of the magnetoelectric hybrid semiactive suspension and the control strategy of PID, which are combined with the AMESim joint simulation model, the design of the Simulink control module is shown in Figure 7. In the Simulink controller model, the displacement signals (Bdisplacement and Wdisplacement) are input, and the current signal obtained by adjusting the parameters through the PID controller is used as the output to achieve the purpose of adjusting the electromagnetic force. The main design parameters of the PID controller are given in Table 4 .

4.3. Simulation Results. In the vibration simulation process of AMESim, the system vibration is controlled and adjusted jointly with the Simulink control module, while setting the simulation parameters in Table 3 , so as to achieve the purpose of simulating the real vibration of the hydraulic damper of the magnetoelectric hybrid suspension.

Here, the three evaluation indexes with the most influential factors are selected: vehicle vertical acceleration, suspension disturbance, and dynamic tire load. Given that this study mainly experiments on the mechanism of the device, it is impossible to consider the comparison of the three performance indicators, so the vertical acceleration of the vehicle body and the dynamic deflection of the suspension are mainly considered, and the vibration displacement curve and acceleration curve of the damper are obtained by simulation.

The magnetoelectric hybrid semiactive suspension and ordinary passive suspension are placed in the same simulation environment. The simulation time sets as $10 \mathrm{~s}$, the sampling time sets as $0.01 \mathrm{~s}$, the white noise amplitude sets as 
TABLE 3: Main simulation parameters.

\begin{tabular}{lcc}
\hline Parameters & Values & Units \\
\hline$m_{s}$ & 400 & $\mathrm{~kg}$ \\
$m_{u}$ & 50 & $\mathrm{~kg}$ \\
$K_{s}$ & 9 & $\mathrm{~N} / \mathrm{mm}$ \\
$K_{t}$ & 10 & $\mathrm{~N} / \mathrm{mm}$ \\
$c$ & 10 & $\mathrm{~N} /(\mathrm{mm} / \mathrm{s})$ \\
$S$ & 2 & $\mathrm{~cm}^{2}$ \\
$H_{c}$ & -8.8 & $\mathrm{KOe}$ \\
$d_{m}$ & 6.5 & $\mathrm{~mm}$ \\
$R_{m}$ & 95 & $\Omega$ \\
$N$ & 100 & $\mathrm{r}$ \\
$\mu_{0}$ & 1 & - \\
\hline
\end{tabular}

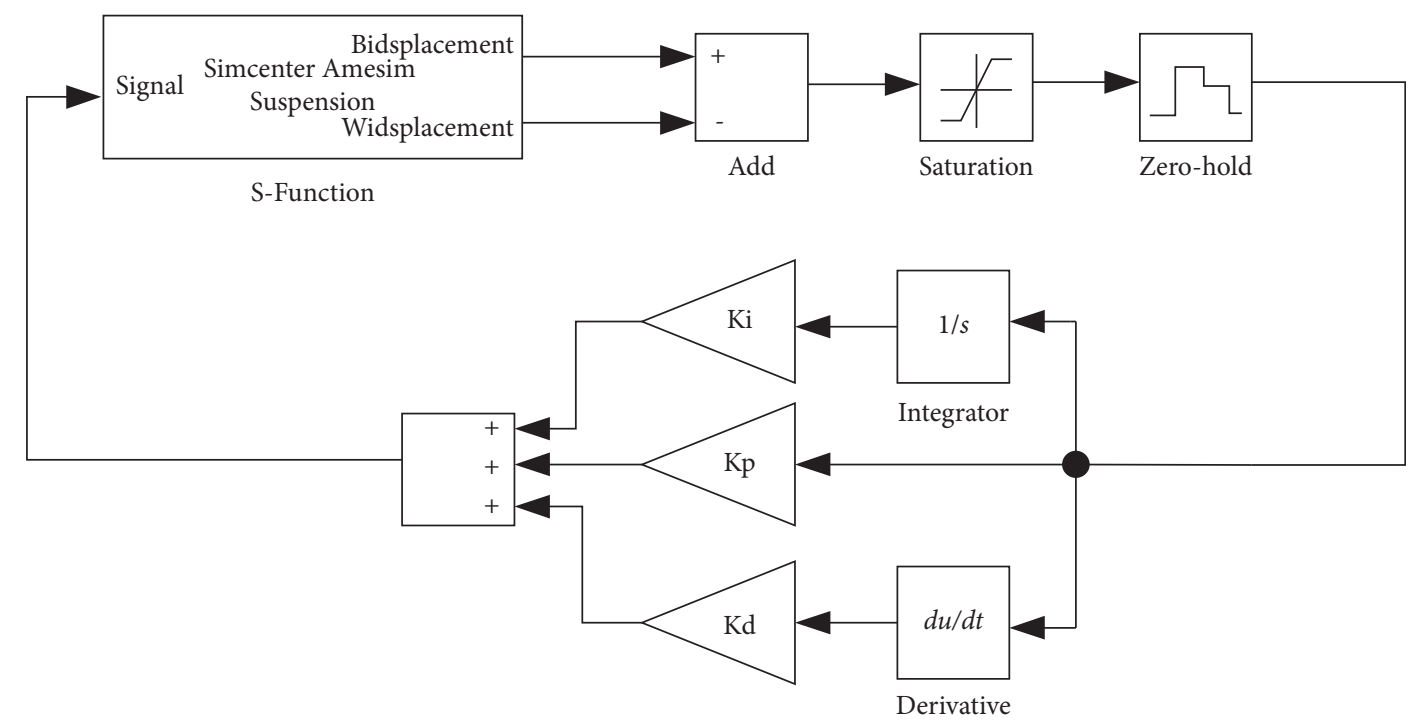

FIGURE 7: Simulink control module.

$4 \mathrm{~mm}$, and the energy sets as 0.1 . Figure 8 shows the PSD information of the excitation signal. Figure 9 shows the simulation curve of dynamic characteristics of magnetoelectric hybrid suspension.

As can be seen from Figure 9, the amplitude of the semiactive suspension vibration curve with the magnetoelectric hybrid suspension hydraulic damper is smaller than that of ordinary passive suspension. On the one hand, for the displacement curve, the amplitude at the first trough is reduced by $33.3 \%$, and the amplitude at the first peak is reduced by $13.5 \%$. The maximum valley difference of the semiactive suspension curve is $6.8 \mathrm{~mm}$, which is $8 \%$ lower than the passive suspension curve. On the other hand, for the acceleration curve, the maximum acceleration with passive suspension is reduced from nearly $2.5 \mathrm{~m} / \mathrm{s}^{2}$ to $0.3 \mathrm{~m} / \mathrm{s}^{2}$ with semiactive suspension. In terms of the curve fluctuation, the semiactive suspension curve is flatter, that is, the suspension disturbance and vehicle body vertical acceleration are lower, the shock absorption effect and the ride comfort of the vehicle are better, and the damping effect is more obvious. The results show that the simulation curve shows some advantages. The next step is to use the experimental device to verify the simulation results.

\section{Establishment of Experimental Platform}

According to Lorentz law, the electromagnetic force in the electromagnetic-permanent magnetic structure can be controlled by changing the voltage in the electromagnet. However, the most direct and easily measured parameters in the magnetoelectric hybrid suspension vibration system are not electromagnetic force and voltage, but the vibration displacement of the hydraulic damper. Therefore, in this study, the vibration displacement of the hydraulic damper is taken as the collection object, and the relevant experimental platform is built. The experimental design includes hardware and software systems. It is expected to complete the verification of the theoretical model by analyzing the vibration displacement curve of the system.

5.1. System Hardware. Data collection and processing consists of hardware and software, and Figure 10 shows the data acquisition hardware system.

The main source of vibration in the vibration system is the shaker. Voltage signals are input to the shaker through the electric control box, and the shaker converts the voltage 
TABLE 4: Main design parameters of the PID controller.

\begin{tabular}{lc}
\hline Parameters & Values \\
\hline$K_{p}$ & 129 \\
$K_{i}$ & 15 \\
$K_{d}$ & 254 \\
\hline
\end{tabular}

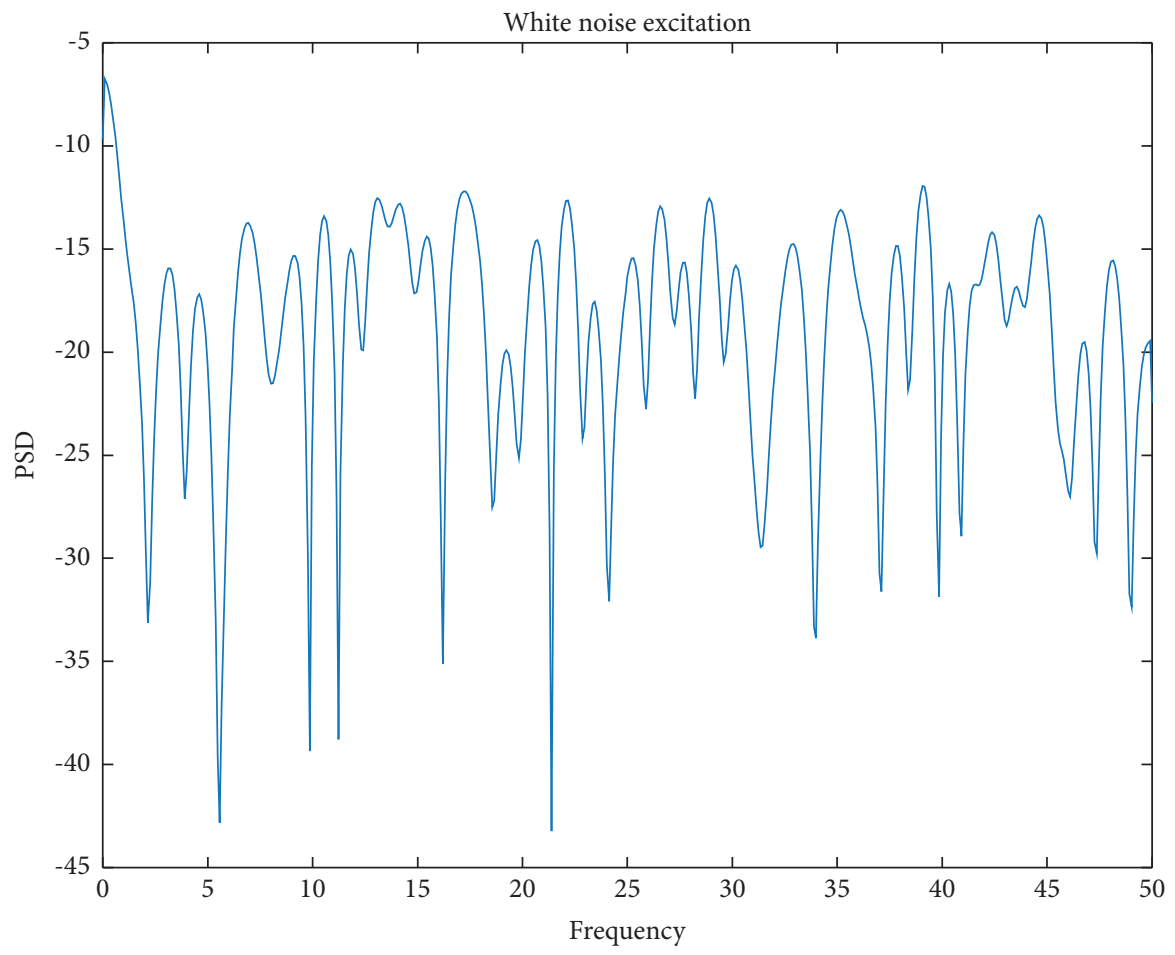

FIGURE 8: PSD information of the excitation signal.

signal into the displacement signal to make the hydraulic damper vibrate. The laser displacement sensor is installed above the hydraulic damper, which is responsible for collecting the vibration displacement signal of the hydraulic damper and converting the displacement signal into the analog voltage signal, as shown in figure. Then, the analog voltage signal is transmitted to the upper computer through the data acquisition card. The upper computer in this study is a personal computer. The data are analyzed and processed by the software program, and the processed voltage signal is transmitted to the driver, which controls the voltage applied to the electromagnet to change the electromagnetic force. After the electromagnetic force is changed, the spring is compressed or stretched by different forces, and the overall vibration absorption performance of the system is changed, resulting in the change of the displacement signal collected by the laser displacement sensor, forming a feedback system. Table 5 provides the main parameters of the system hardware selection.

After the experimental device is designed, the experimental platform can be built. According to the structure model and working principle of the designed magnetoelectric hybrid suspension hydraulic damper, the hydraulic damper can be placed vertically, and from bottom to top are the vibrator-base (acting as a connection between the exciter and the hydraulic damper)-hydraulic damper-vibrating table (i.e., bracket, used to fix and limit the amplitude of the system), the microlaser displacement sensor is fixed on the vibrating table and connected to the data acquisition card. Figure 11 shows the principle of the hardware system, Figure 12 shows the test system, and Figure 13 shows the hydraulic damper experimental device.

\section{Experiment and Analysis}

6.1. Experiment and Simulation Comparison. After the experimental platform and control system are built, the overall vibration damping performance of the system is verified experimentally. In order to compare with the simulation results, the white noise signal with the same waveform is selected for the excitation signal of the shaker, and Figure 14 shows the comparison curve.

As can be seen from the graph, the experimental curve fluctuations compared with the simulation curve are bigger due to the inevitable error of the experimental device and the delay of data collection and processing. Comparing the upper and lower peak values of the displacement curve obtained by the experimental device and AMESim simulation, it can be concluded that the arithmetic mean of the error is $0.33 \mathrm{~mm}$, and the error is within $10 \%$. For the 


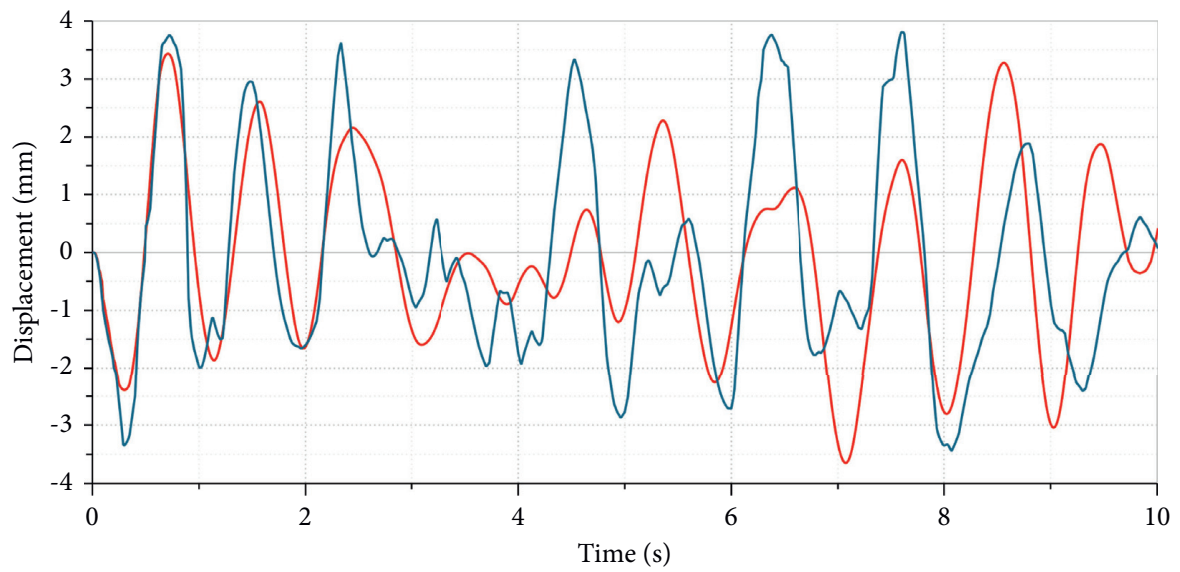

- Passive Suspension

- Semi-active Suspension

(a)

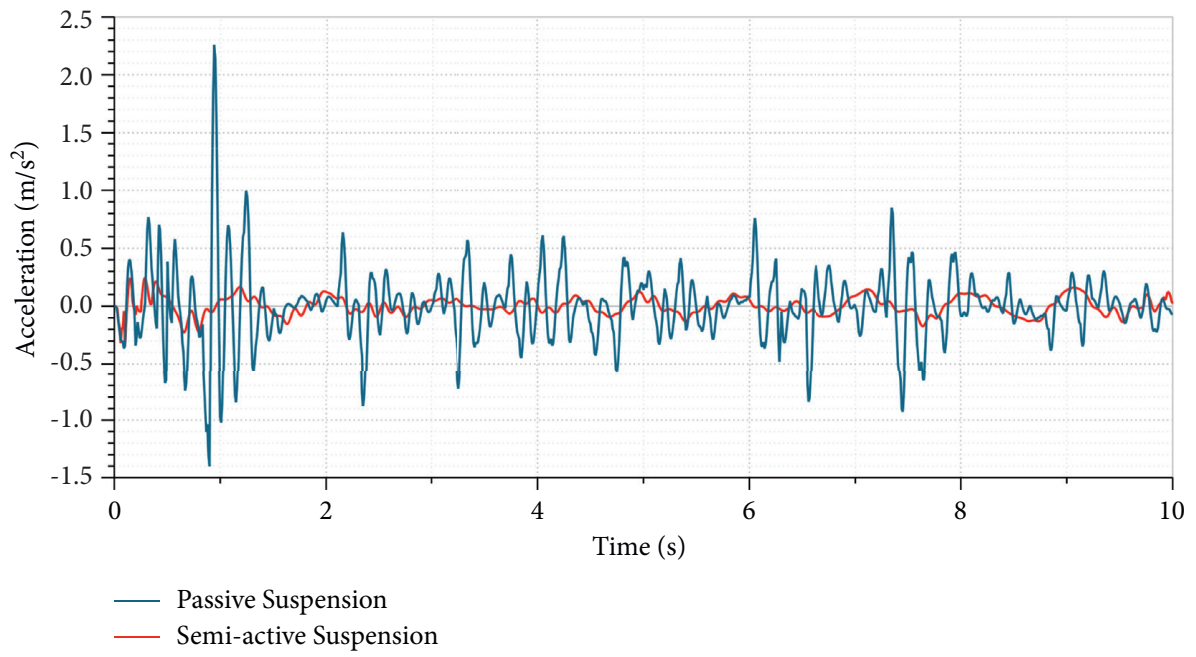

(b)

FIgURE 9: Simulation curve of dynamic characteristics of magnetoelectric hybrid suspension. (a) Displacement curve. (b) Acceleration curve.

acceleration curve shown in figure, the curve obtained by the experiment has a larger error compared with the simulation, which is mainly due to the error caused by the external uncertain disturbance. When the vibration curve is between 0 and $2 \mathrm{~s}$, the vibration amplitude reaches a larger value, and the curve fluctuation tends to slow down as time goes on.

The experimental graph shows that the experimental results of the semiactive suspension of the new magneticelectric hybrid suspension hydraulic damper verify the theoretical model. The above two effects are consistent, and both can achieve the vibration reduction effect, and the error is within the allowable range.

6.2. Analysis of Experimental Results. In order to reflect the superiority of the semiactive suspension damping effect of the new hydraulic damper, the damping performance of the semiactive suspension and the passive suspension are compared. Due to the limitations of the experimental device, the vibration experiments of the hydraulic damper under the limited bandwidth white noise excitation signal when the electromagnet current is turned on and when the electromagnet current is not turned on are, respectively, carried out to simulate the actual vibration reduction environment of semiactive suspension and passive suspension. Figure 15 shows the comparison curve, Table 6 provides the comparison of peak and root mean square values of passive suspension and semiactive suspension about displacement curve, and Table 7 provides the comparison of peak and root mean square values of acceleration curves.

As can be seen from Table 6, the semiactive suspension system is obviously superior to the passive suspension in terms of the vibration reduction effect, with a difference of around $20 \%$. In other words, compared with the passive suspension, the semiactive suspension with the new hydraulic damper has a certain advantage in the vibration reduction rate of around $20 \%$.

On the one hand, the acceleration curve can directly reflect the stress state of the system, thus reflecting the changing characteristics of the system stiffness. On the other 


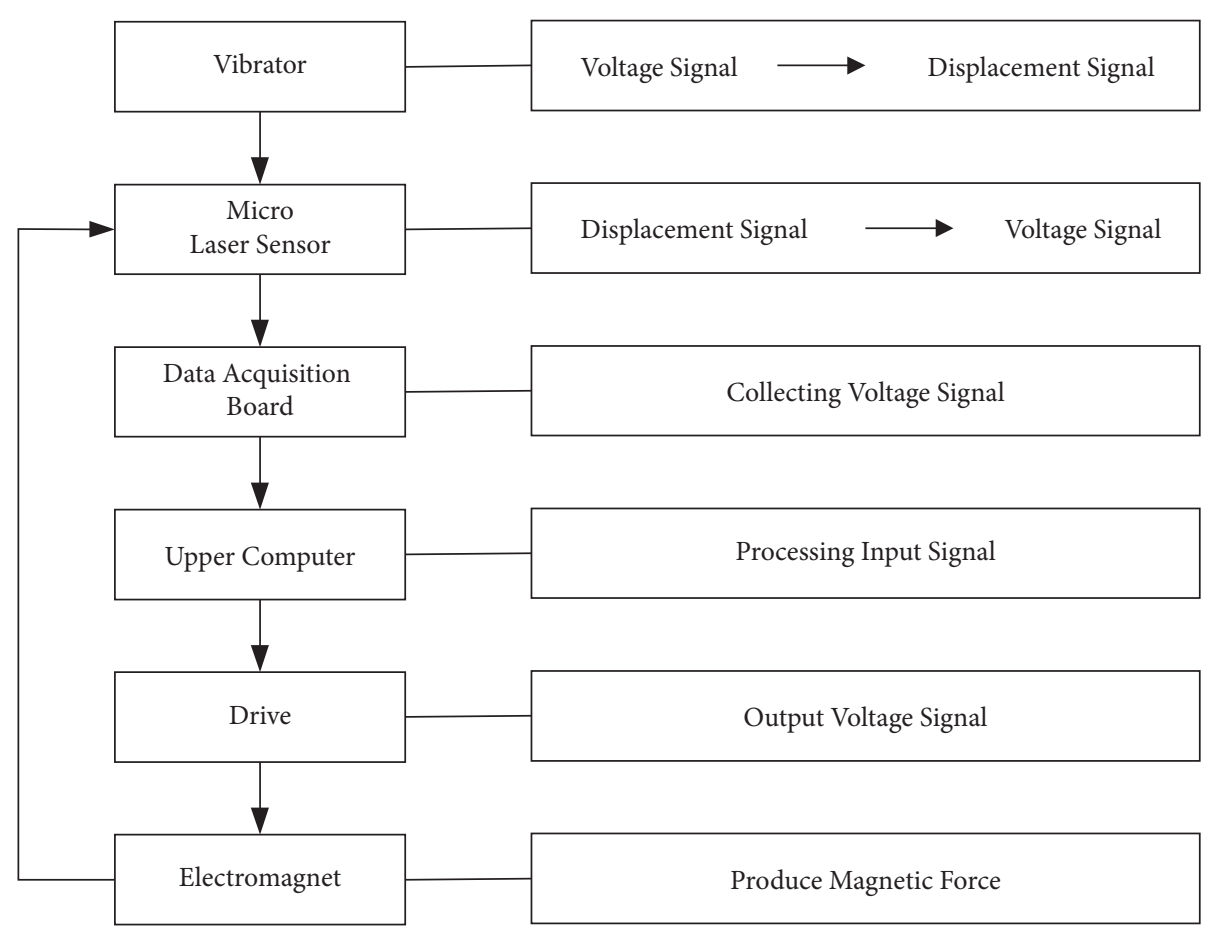

FIGURE 10: Data acquisition hardware system.

TABLE 5: Main parameters.

\begin{tabular}{|c|c|}
\hline Devices & Parameters \\
\hline Vibrator (JZ-20) & $\begin{array}{l}\text { Maximum output force } 200 \mathrm{~N} \\
\text { Working frequency DC } \sim 2 \mathrm{KHz} \\
\text { Maximal displacement } \pm 10 \mathrm{~mm}\end{array}$ \\
\hline Permanent magnets (Nd2Fe14B) & $\begin{array}{c}\text { Cylindrical } \Phi 40 \times 10 \mathrm{~mm} \text {, thickness } 6.5 \mathrm{~mm} \\
\text { Grade } \mathrm{N} 35 \\
\text { Magnet remanence } \mathrm{Br}=1.18 \text { tesla } \\
\text { Permanent magnet coercivity } \mathrm{Hc}=-8.8 \mathrm{KOe}\end{array}$ \\
\hline Electromagnet (XDA-40/20) & $\begin{array}{c}\text { Suction } 25 \mathrm{~kg} \\
\text { Voltage } 24 \mathrm{~V} \varnothing \\
\text { Cylindrical diameter } 40 \mathrm{~mm} \text {, height } 25 \mathrm{~mm} \\
\text { Power } 8 \mathrm{~W} \\
\text { Weight } 150 \mathrm{~g}\end{array}$ \\
\hline Carbon steel spring & $\begin{array}{c}\text { Wire diameter } 2 \mathrm{~mm} \\
\text { Outer diameter } 35 \mathrm{~mm} \\
\text { Height } 25 \mathrm{~mm} \\
\text { Number of turns } 4\end{array}$ \\
\hline Microlaser sensor (HG-C1050) & $\begin{array}{c}\text { Range } 10 \mathrm{~mm} \\
\text { Measuring range } 30 \pm 5 \mathrm{~mm} \\
\text { Accuracy } 10 \mu \mathrm{m} \\
\text { Sampling frequency } 2 \mathrm{kHz}\end{array}$ \\
\hline Drive (AQMD3610NS) & $\begin{array}{c}\text { Voltage } 9-36 \mathrm{~V} \\
\text { Maximum output current } 10 \mathrm{~A} \\
\text { Accuracy } 0.1 \mathrm{~A}\end{array}$ \\
\hline Data acquisition board (MCC-1608G) & $\begin{array}{l}\text { Highest sampling rate } 250 \mathrm{kS} / \mathrm{s} \\
32 \mathrm{bit} \\
\text { 16-Channel single-terminal, } 8 \text {-channel differential analog input }\end{array}$ \\
\hline
\end{tabular}

hand, in the case that the acceleration curve fluctuates smoothly, the ride comfort of the car is better. As can be seen from Table 7, compared with the passive suspension, the semiactive suspension system has less fluctuation in the vertical acceleration of the vehicle body subjected to vibration, and the difference is about $10 \%$. The experiment 


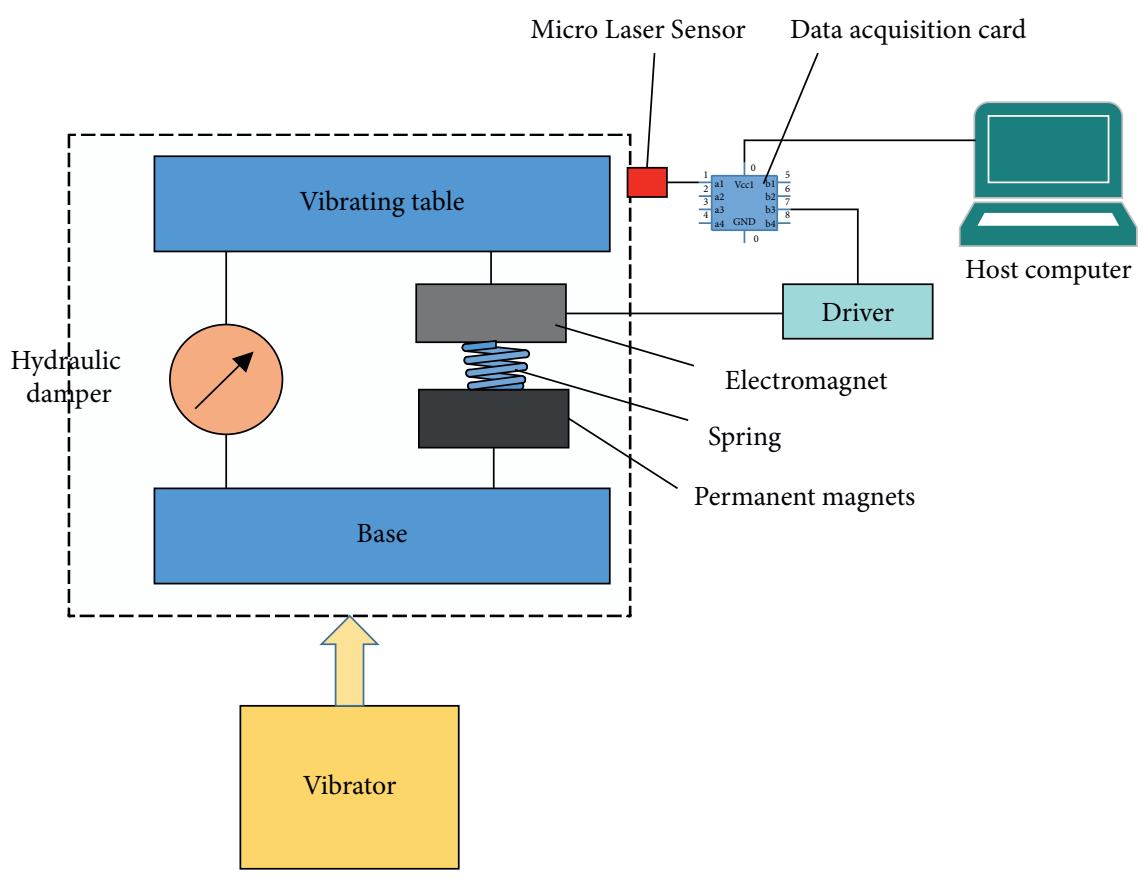

FIgURE 11: Principle of the hardware system.

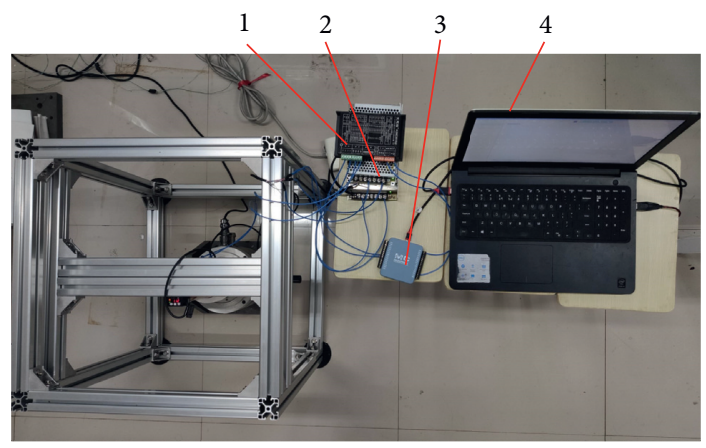

FIgURE 12: Test system. 1, drive; 2, power supply; 3, data acquisition board; 4, upper computer.

shows that compared with passive suspension, the semiactive suspension of the new hydraulic damper has a certain advantage in the comfort of around $10 \%$.

In order to get a better display of all the above curve results, Figure 16 shows the power spectral density diagram of semiactive suspension and passive suspension simulation and experiment. The PSDs show that the control force of the semiactive suspension has a better control effect in both lowand high-frequency regions.

\section{Study on Variable Stiffness of the Damper}

The purpose of introducing magnetoelectric hybrid suspension into the hydraulic damper is to make the stiffness of the system controllable. Therefore, it is necessary to conduct an experimental comparison of the system with variable stiffness under different voltages, which can prove that changing the voltage of the input electromagnet can change the stiffness of the system and find the most suitable voltage value. Figure 17 shows the control program block diagram.

As can be seen from the Figure 17, the program block diagram for the closed-loop feedback control, control module has two main functions: data processing and preservation; the displacement signal and voltage signal conversion, filtering, and processing: intelligent discriminant of the vibrator vibration signal of different to choose the appropriate voltage amplitude of the signal input in the drive, which can adjust the vibration.

This experiment device of electromagnet rated voltage for $24 \mathrm{~V}$, in order to choose the appropriate voltage signal, a smart choice in the control program module, small vibration amplitude, vibration wave as smooth as the premise, to select the optimal damping effect than that of the voltage signal value $-18 \mathrm{~V}$, as same as the above limited bandwidth white noise signal as excitation source vibration experiments. On the premise of stiffness change, two other comparable input 


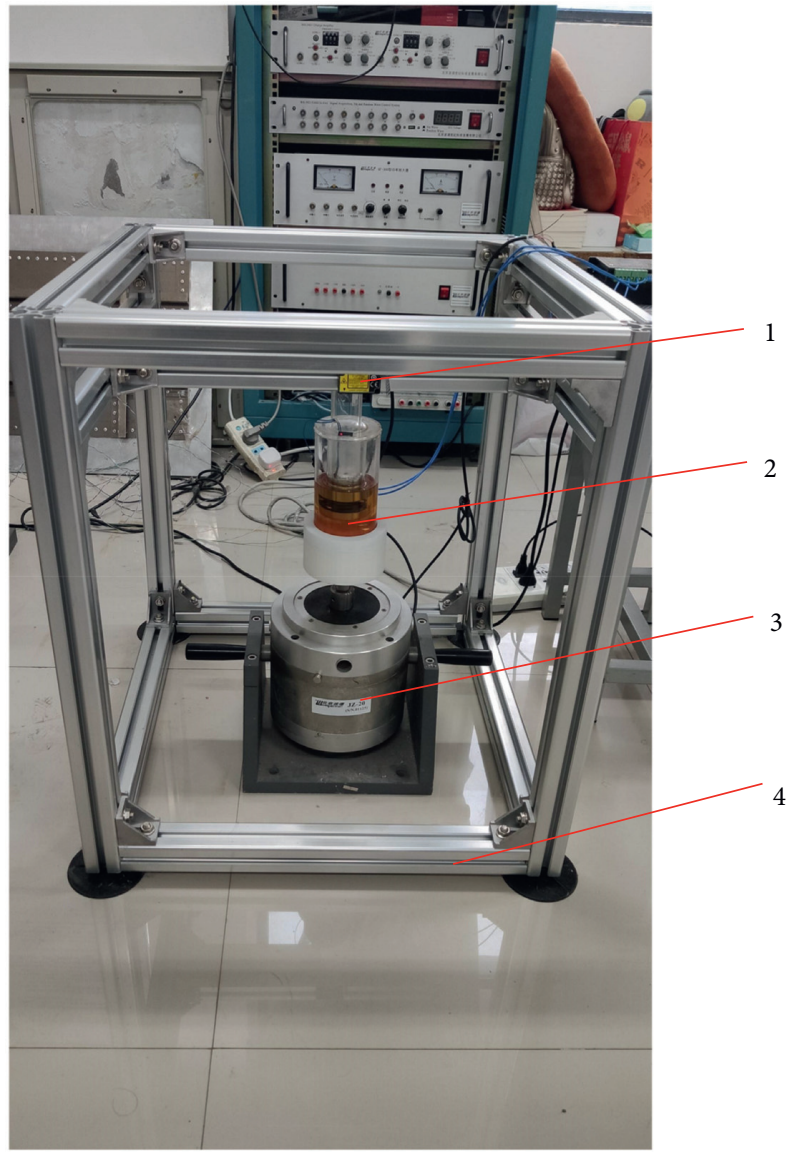

FIGURE 13: Hydraulic damper experimental device. 1, micro laser sensor; 2, hydraulic damper; 3, vibrator; 4, support.

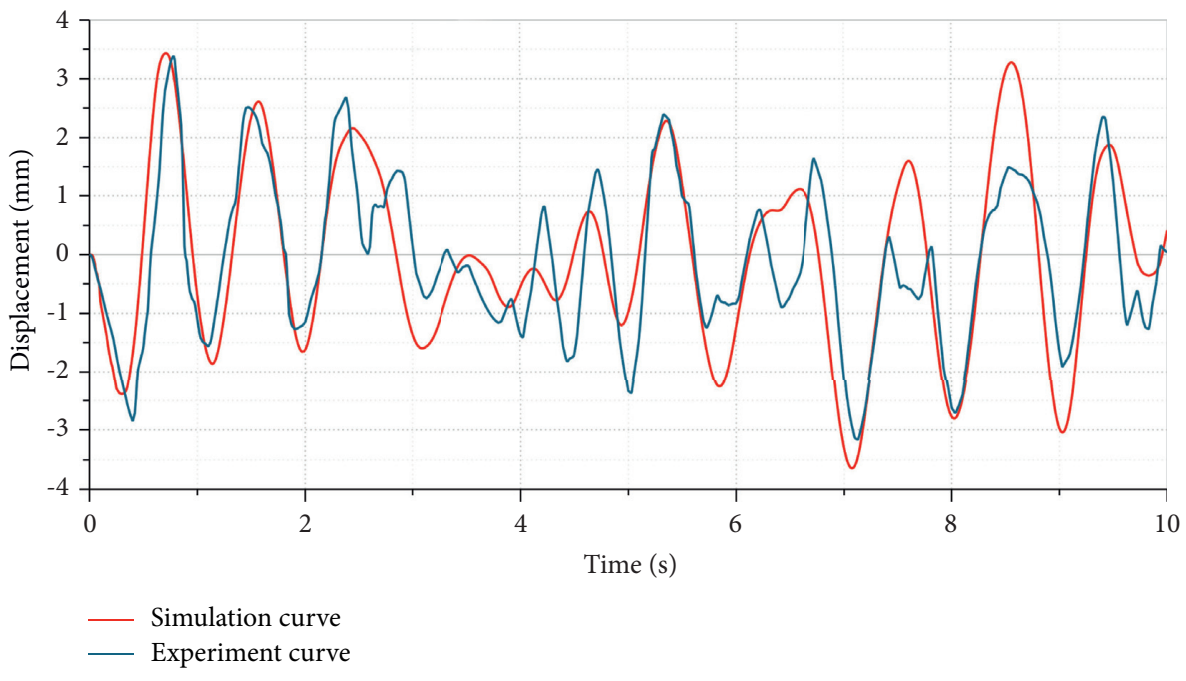

(a)

Figure 14: Continued. 


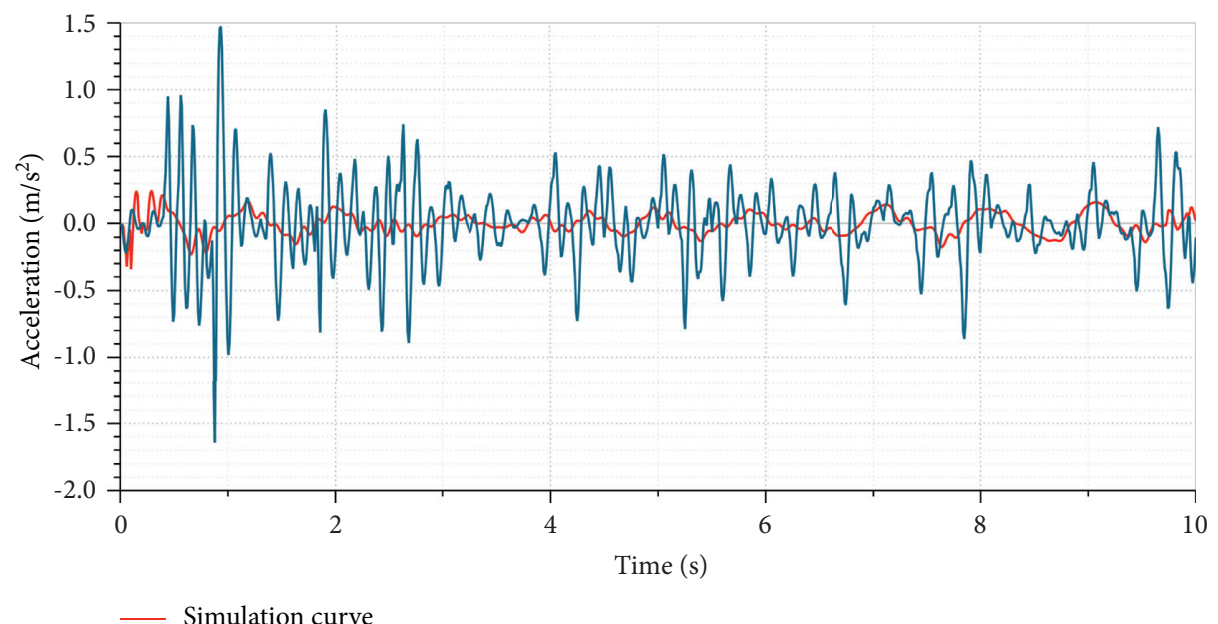

(b)

Figure 14: Comparison curve between experiment and simulation. (a) Displacement curve. (b) Acceleration curve.

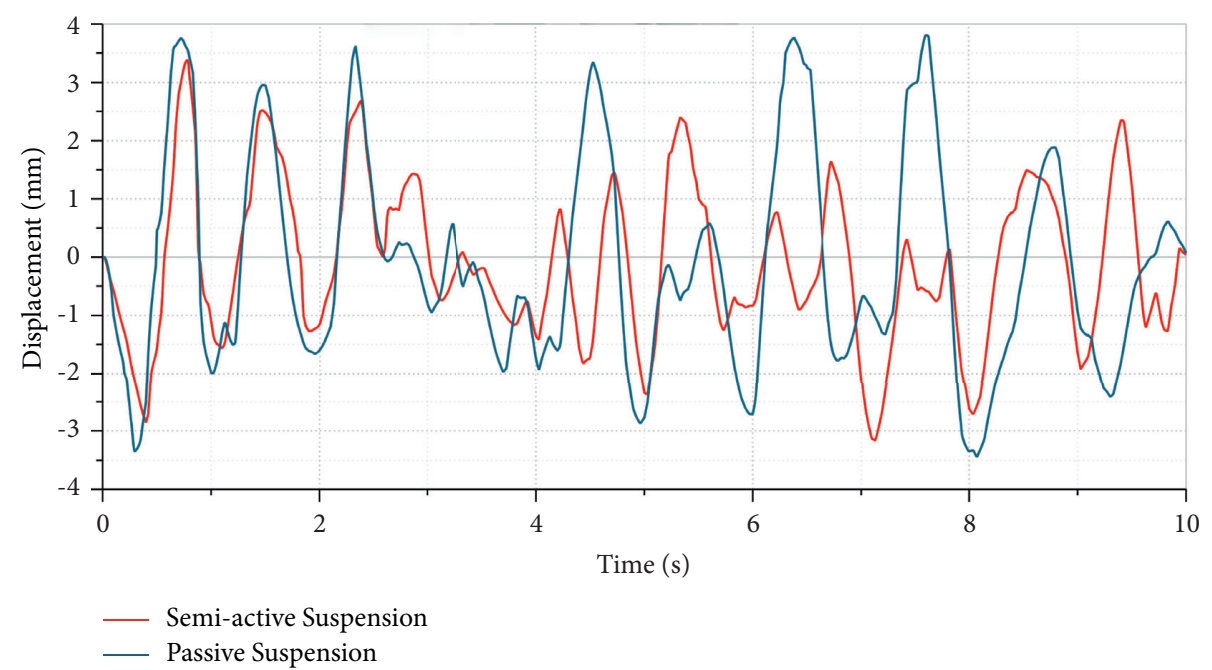

(a)

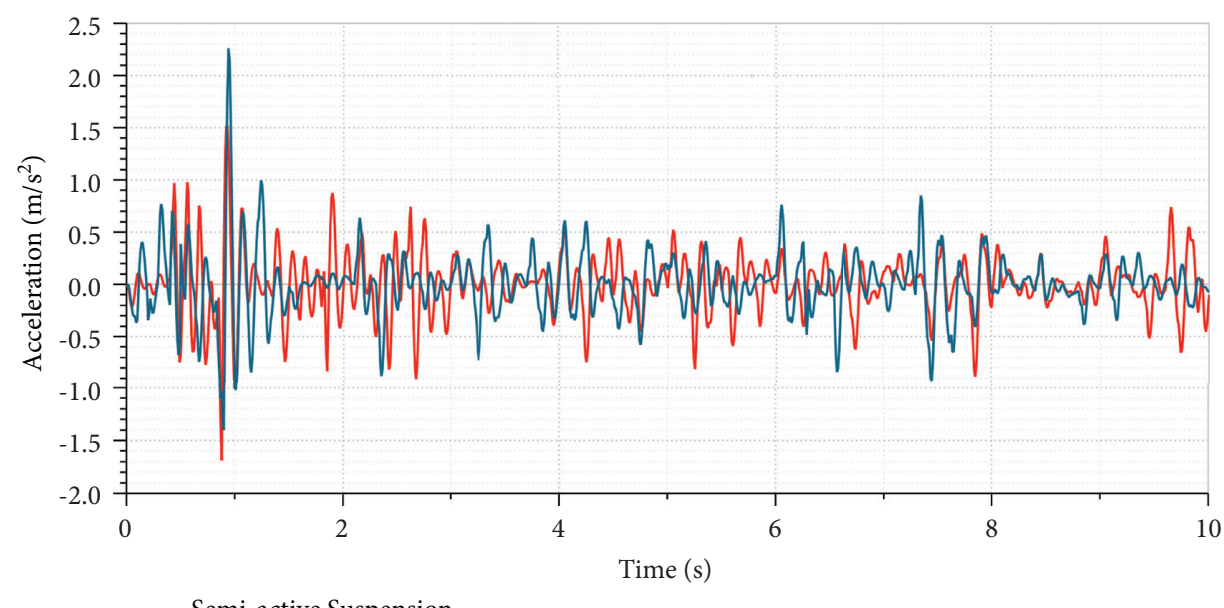

- Semi-active Suspension

- Passive Suspension

(b)

Figure 15: Suspension dynamic characteristic curve of the experiment. (a) Displacement curve. (b) Acceleration curve. 
TABLE 6: Comparison of peak and RMS values of displacement curve.

\begin{tabular}{lcccc}
\hline Times $(\mathrm{s})$ & Values & Passive suspension $(\mathrm{mm})$ & Semiactive suspension $(\mathrm{mm})$ & Difference value $(\mathrm{mm})$ \\
\hline \multirow{4}{*}{$0-2$} & Trough & -3.49867 & -2.85341 & 0.64526 \\
& Peak & -3.76981 & 3.42565 & 0.34416 \\
& RMS & 2.0776 & 1.7364 & 0.3412 \\
\hline \multirow{3}{*}{$2-4$} & Trough & -1.97310 & -1.34572 & 0.62738 \\
& Peak & 3.64241 & 2.72142 & 0.92099 \\
& RMS & 1.5772 & 1.1075 & 0.4715 \\
\hline \multirow{4}{*}{$4-6$} & Trough & -2.87718 & -2.37772 & 0.49946 \\
& Peak & 3.36132 & 2.41032 & 0.95100 \\
& RMS & 1.7660 & 1.2627 & 0.5033 \\
$6-8$ & Trough & -3.35022 & -3.16528 & 0.18442 \\
& Peak & 3.80681 & 1.66328 & 2.14353 \\
$8-10$ & RMS & 2.4202 & 1.1664 & 1.0117 \\
& Trough & -3.4508 & -2.7342 & 0.72738 \\
& Peak & 1.88574 & 2.34674 & 0.46100 \\
\hline
\end{tabular}

TABLE 7: Comparison of peak and RMS values of acceleration curve.

\begin{tabular}{lcccc}
\hline Times $(\mathrm{s})$ & Values & Passive suspension $(\mathrm{mm})$ & Semiactive suspension $(\mathrm{mm})$ & Difference value $(\mathrm{mm})$ \\
\hline \multirow{4}{*}{$0-2$} & Trough & -1.40957 & -1.68653 & -0.27696 \\
& Peak & 2.27068 & 1.52635 & 0.74433 \\
& RMS & 0.6460 & 0.6136 & 0.0324 \\
\hline \multirow{4}{*}{$2-4$} & Trough & -0.91531 & -0.88261 & 0.03270 \\
& Peak & 0.65425 & 0.75323 & -0.09898 \\
& RMS & 0.3371 & 0.3125 & 0.0246 \\
$4-6$ & Trough & -0.59587 & -0.81253 & -0.21666 \\
& Peak & 0.62876 & 0.52378 & 0.10498 \\
& RMS & 0.3096 & 0.2628 & 0.027 \\
$6-8$ & Trough & -0.93276 & -0.88021 & 005255 \\
& Peak & 0.86323 & 0.49212 & 0.37111 \\
& RMS & 0.3755 & 0.3177 & 0.0578 \\
$8-10$ & Trough & -0.39879 & -0.66213 & -0.26334 \\
& Peak & 0.31252 & 0.47869 & -0.16617 \\
& RMS & 0.1754 & 0.2021 & -0.0267 \\
\hline
\end{tabular}

voltage signals, respectively, $12 \mathrm{~V}$ and $24 \mathrm{~V}$, are selected and vibration reduction experiments are carried out under the same conditions. Figure 18 shows the results.

As can be seen from the displacement comparison curve in Figure 18, when the input voltage of the electromagnet is $18 \mathrm{~V}$, the displacement and acceleration vibration curve of the damper are located in the relatively middle position, the amplitude of the damper fluctuates more stable, and the response speed is faster. When the input voltage of the electromagnet is reduced to $12 \mathrm{~V}$, it can be seen from the experimental results and the quantitative relationship obtained from the previous analysis that the system stiffness is reduced compared with the former, and the amplitude of the vibration curve fluctuates less, but the response speed is slower. When the voltage of the input electromagnet is increased to $24 \mathrm{~V}$, the stiffness of the system is relatively improved, and the amplitude of the vibration curve is increased. Meanwhile, the power consumption of the solenoid at the rated voltage of $24 \mathrm{~V}$ is larger.

The experimental results show that when the input voltage signal is the optimal value of the system vibration damping effect, the system stiffness is higher, and the system vibration amplitude becomes larger when the voltage signal increases. When the voltage signal decreases, the system stiffness and amplitude decrease, but the system response speed is slower. The experimental results are consistent with the theoretical results above, that is, the stiffness of the system can be adjusted by adjusting the input voltage value. 

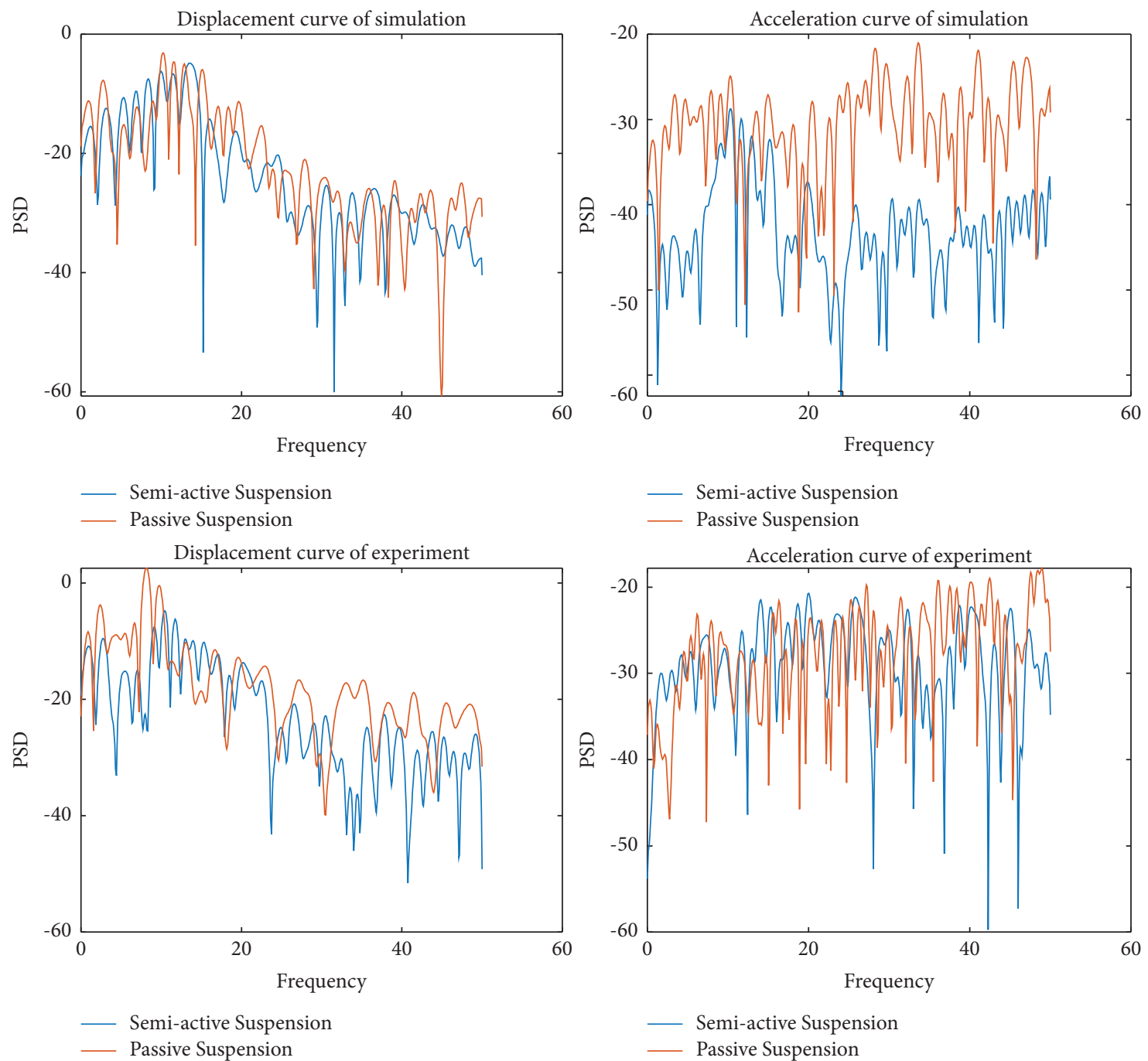

Figure 16: PSDs of simulation and experiment.

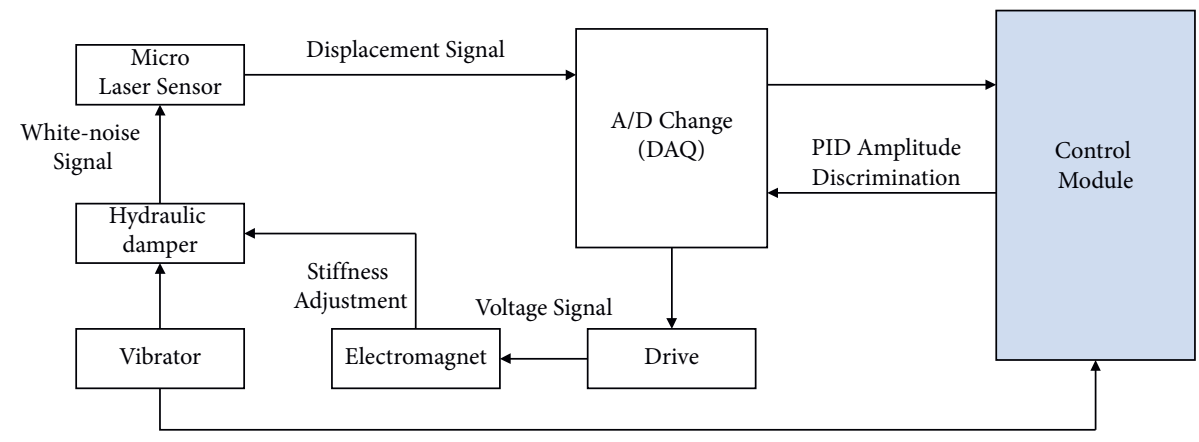

FIgURE 17: Control program block diagram. 


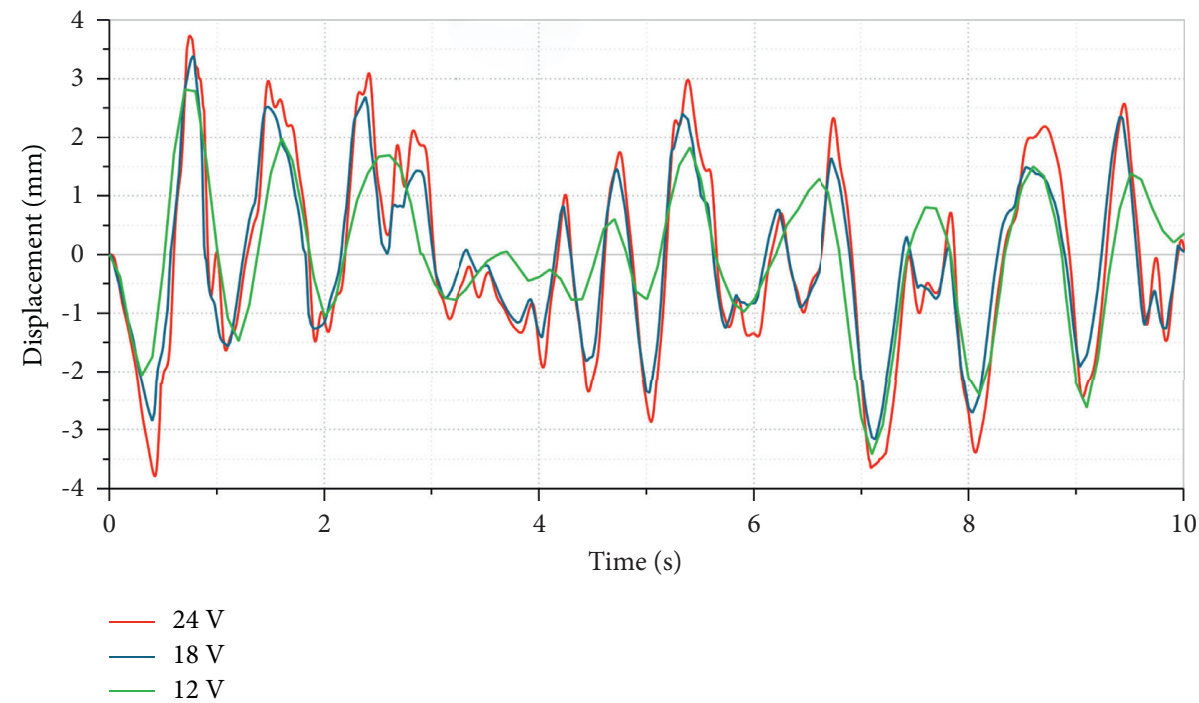

(a)

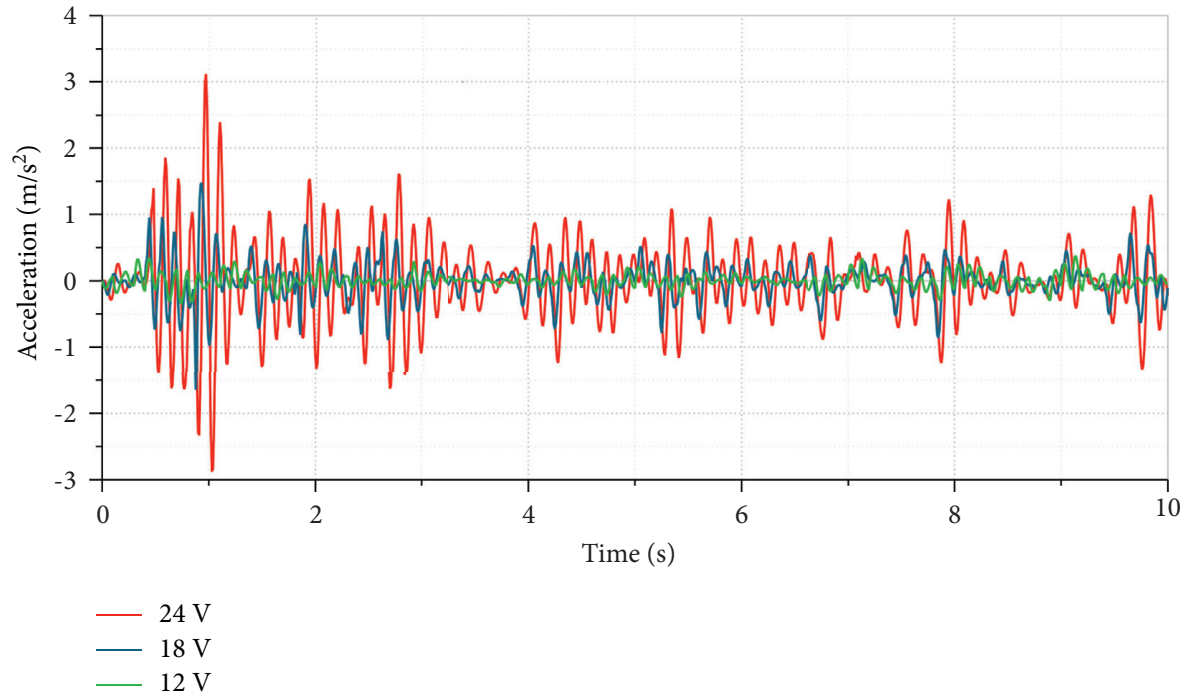

(b)

Figure 18: Vibration comparison experiment under different voltage input. (a) Displacement curve. (b) Acceleration curve.

\section{Conclusion}

A new type of magnetoelectric hybrid suspension hydraulic damper is proposed by introducing magnetoelectric hybrid suspension structure on the basis of the spring-damping suspension system. In the damper, the electromagneticpermanent magnet suspension structure is used to adjust the vibration of the system. According to the established structure model combined with its working principle, the method of joint analysis of magnetic circuit and oil circuit is adopted to obtain the expression of electromagnetic force and damping force. By analyzing the mathematical model of the 2-DOF $1 / 4$ chassis vibration damping system, the mathematical model of the equivalent stiffness and equivalent damping of the system and the space state equation of the system are obtained.
According to the structural model, a two-degree-offreedom quarter vehicle AMESim simulation model is established, and the Simulink control model is established from the state equation in the vibration system. White noise with limited bandwidth is used as the road irregularity signal, PID is used as the control strategy, and AMESim/ Simulink cosimulation is carried out meanwhile. The vibration test bench is set up to verify the rationality of the theoretical model and the simulation model. The experimental results show that the semiactive suspension system equipped with the new magnetoelectric hybrid suspension hydraulic damper has a better damping effect than the ordinary passive suspension system, with the displacement amplitude reduced by $20 \%$ and the acceleration amplitude reduced by $10 \%$. By adjusting the input voltage, the vibration curve of the system can be changed, and the optimal voltage 
value of the system is $18 \mathrm{~V}$, which proves that the stiffness of the designed damper has certain controllability.

\section{Data Availability}

The dynamic model data used to support the findings of this study are included within the article and references.

\section{Disclosure}

Kun $\mathrm{Hu}$ and Fei Li are the co-first authors.

\section{Conflicts of Interest}

The authors declare that there are no conflicts of interest.

\section{Authors' Contributions}

Kun $\mathrm{Hu}$ and Fei Li contributed equally to this work.

\section{Acknowledgments}

This work was supported by the National Nature Science Foundation of China (51874004 and 51904007), Key Research and Development Program of Anhui Province, China (202004a07020043), and National Key Research and Development Program (2020YFB1314203).

\section{References}

[1] P. Novak, T. Kot, J. Babjak, Z. Konecny, W. Moczulski, and A. Rodriguez Lopez, "Implementation of explosion safety regulations in design of a mobile robot for coal mines," Applied Sciences-basel, vol. 11, p. 1300, 2018.

[2] D. Zhu, X. Sun, S. Liu, and P. Guo, "A SLAM method to improve the safety performance of mine robot," Safety Science, vol. 120, pp. 422-427, 2019.

[3] T. Lou, S. Jiang, J. Han, and H. Sun, "Auto disturbances refection visual servoing control for excavator robot based on particle swarm optimization," Metallurgical and Mining Industry, vol. 7, no. 6, pp. 40-44, 2015.

[4] R. S. Sharp and S. A. Hassan, "The relative performance capabilities of passive, active and semi-active car suspension systems," Proceedings of the Institution of Mechanical Engineers - Part D: Transport Engineering, vol. 200, no. 3, pp. 219-228, 1986.

[5] S. Jain, S. Saboo, C. I. Pruncu, and D. R. Unune, "Performance investigation of integrated model of quarter car semi-active seat suspension with human model," Applied Sciences, vol. 10, no. 9, p. 3185, 2020.

[6] W. G. Ata and A. M. Salem, "Semi-active control of tracked vehicle suspension incorporating magnetorheological dampers," Vehicle System Dynamics, vol. 55, no. 5, pp. 626-647, 2017.

[7] B. Yang and H. Tang, "Identification of dynamic load of air suspension system," Transactions of the Chinese Society of Agricultural Engineering, vol. 26, no. 3, pp. 130-134, 2010.

[8] C. Gracia-Fernández, S. Gómez-Barreiro, A. Elmoumni, A. Álvarez, J. López-Beceiro, and R. Artiaga, "Simultaneous application of electro and orthogonal superposition rheology on a starch/silicone oil suspension," Journal of Rheology, vol. 60, no. 1, pp. 121-127, 2016.

[9] P. S. Gokul and M. K. Malar, "Analytical approach for the design of convoluted air suspension and experimental validation," Acta Mechanica Sinica, vol. 35, no. 5, pp. 1093-1103, 2019.

[10] Z. Sang, M. Dong, Y. Qin, and L. Gu, "Modellin and analysis on the characteristics of dual-chamber hydro-pneumatic suspension," Transactions of Beijing Institute of Technology, vol. 37, no. 4, pp. 401-405, 2017.

[11] A. J. Nieto, A. L. Morales, J. R. Trapero, J. M. Chicharro, and P. Pintado, "An adaptive pneumatic suspension based on the estimation of the excitation frequency," Journal of Sound and Vibration, vol. 330, no. 9, pp. 1891-1903, 2011.

[12] I. Maciejewski, T. Krzyzynski, and H. Meyer, "Modeling and vibration control of an active horizontal seat suspension with pneumatic muscles," Journal of Vibration and Control, vol. 24, no. 24, pp. 5938-5950, 2018.

[13] P. Pintado, C. Ramiro, A. L. Morales, A. J. Nieto, and J. M. Chicharro, "The dynamic behavior of pneumatic vibration isolators," Journal of Vibration and Control, vol. 24, no. 19, pp. 4563-4574, 2018.

[14] Z. Zhu, R. Wang, L. Yang, Z. Sun, and X. Meng, "Modelling and control of a semi-active dual-chamber hydro-pneumatic inerter-based suspension system," Proceedings of the Institution of Mechanical Engineers - Part D: Journal of Automobile Engineering, vol. 235, no. 9, pp. 2355-2370, 2021.

[15] J. Zhao, P. K. Wong, X. Ma, and Z. Xie, "Design and analysis of an integrated sliding mode control-two-point wheelbase preview strategy for a semi-active air suspension with stepper motor-driven gas-filled adjustable shock absorber," Proceedings of the Institution of Mechanical Engineers-Part I: Journal of Systems \& Control Engineering, vol. 232, no. 9, pp. 1194-1211, 2018.

[16] R. Jeyasenthil and S. B. Choi, "A novel semi-active control strategy based on the quantitative feedback theory for a vehicle suspension system with magneto-rheological damper saturation," Mechatronics, vol. 54, pp. 36-51, 2018.

[17] Y. Huang, J. Na, X. Wu, G.-B. Gao, and Y. Guo, "Robust adaptive control for vehicle active suspension systems with uncertain dynamics," Transactions of the Institute of Measurement and Control, vol. 40, no. 4, pp. 1237-1249, 2018.

[18] C. C. Wang, T. E. Lee, K. H. Hsia, L. S. Ma, and Y. C. Hsieh, “A multi-sensor suspension robot for autonomous detection and surveillance," Applied Mechanics and Materials, vol. 190-191, pp. 634-637, 2012.

[19] J. Ding, X. Yang, Z. Long, and N. Dang, “Three-dimensional numerical analysis and optimization of electromagnetic suspension system for $200 \mathrm{~km} / \mathrm{h}$ maglev train considering eddy current effect," IEEE Access, vol. 6, pp. 61547-61555, 2018.

[20] S. Emre and B. Pinar, "Optimization of suspension system and sensitivity analysis for improvement of stability in a midsize heavy vehicle," Engineering Science and Technology An International Journal, vol. 20, pp. 997-1012, 2017.

[21] E. Babak, B. Hamidreza, B. K. Mir, and G. Farid, "A hybrid electromagnetic shock absorber for active vehicle suspension systems," Vehicle System Dynamics, vol. 49, no. 1-2, pp. 311-332, 2011.

[22] I. Maciejewski, T. Krzyżyński, S. Pecolt, and S. Chamera, "Semi-active vibration control of horizontal seat suspension by using magneto-rheological damper," Journal of Theoretical and Applied Mechanics, vol. 57, no. 2, pp. 411-420, 2019.

[23] M. Mohammed and M. H. R. Alktranee, "Parametric analysis of vehicle suspension based on air spring and MR damper with semi-active control," Journal of Physics: Conference Series, vol. 1773, no. 1, pp. 1-13, 2021. 
[24] M.-e.-H. Jamadar, R. M. Desai, R. S. T. Saini, H. Kumar, and S. Joladarashi, "Dynamic analysis of a quarter car model with semi-active seat suspension using a novel model for magnetorheological (MR) damper," Journal of Vibration Engineering \& Technologies, vol. 9, no. 1, pp. 161-176, 2021.

[25] R. Ding, R. Wang, X. Meng, and L. Chen, "Energy consumption sensitivity analysis and energy-reduction control of hybrid electromagnetic active suspension," Mechanical Systems and Signal Processing, vol. 134, 2019.

[26] B. L. J. Gysen, J. J. H. Paulides, J. L. G. Janssen, and E. A. Lomonova, "Active electromagnetic suspension system for improved vehicle dynamics," IEEE Transactions on Vehicular Technology, vol. 59, no. 3, pp. 1156-1163, 2010.

[27] A. Nandi and S. Neogy, "Performance analysis of a hybrid one-sided magnetic exciter mounted on a piezoelectric stack," Shock and Vibration, vol. 17, no. 2, pp. 205-215, 2010.

[28] S. Xu, X. Liu, and Y. Le, "Electromagnetic design of a highspeed solid cylindrical permanent-magnet motor equipped with active magnetic bearings," IEEE Transactions on Magnetics, vol. 53, no. 8, pp. 1-15, 2017.

[29] Y.-H. Wang and M.-C. Shih, "Effect of a hybrid controller on ride comfort under random road excitation for a semi-active suspension system," Journal of Automobile Engineering, vol. 226, no. 12, pp. 1640-1651, 2012.

[30] Y. Li, C. Xie, S. Quan, W. Li, and Y. Shi, "Maximization of piezoelectric vibration energy harvesting of vehicle based on double-gear drive," Energy Science \& Engineering, vol. 7, no. 5, pp. 1948-1960, 2019.

[31] H. Taghavifar and S. Rakheja, "Parametric analysis of the potential of energy harvesting from commercial vehicle suspension system," Proceedings of the Institution of $\mathrm{Me}$ chanical Engineers - Part D: Journal of Automobile Engineering, vol. 233, no. 11, pp. 2687-2700, 2019.

[32] T. Darabseh, D. Al-Yafeai, A.-H. I. Mourad, and F. Almaskari, "Piezoelectric method-based harvested energy evaluation from car suspension system: simulation and experimental study," Energy Science and Engineering, vol. 9, pp. 1-17, 2020.

[33] W. Zhang, M. Liu, L. Y. Xu, X. P. Zhao, and X. Fu, "Simulation of hydraulic suspension system of electric tractor based on matlab-AMESim," Journal of Physics: Conference Series, vol. 1903, no. 1, pp. 1-8, 2021.

[34] L. Cao, G. Xu, G. Su, J. Cui, Y. Cai, and H. Cao, "Design of automatic pressurizing device of hydraulic support initial force," Energy Science \& Engineering, vol. 8, no. 8, pp. 2868-2877, 2020. 